\title{
In Vitro Characterization of a Biaryl Amide Anti-virulence Compound Targeting Candida albicans Filamentation and Biofilm Formation
}

\section{OPEN ACCESS}

Edited by:

Priya Uppuluri,

University of California, Los Angeles,

United States

Reviewed by:

Nuno Pereira Mira,

Instituto de Bioengenharia e

Biociências (IBB), Portugal

Guillermo Quindós,

University of the Basque Country

(UPV/EHU), Spain

${ }^{*}$ Correspondence:

Jose L. Lopez-Ribot jose.lopezribot@utsa.edu

Received: 17 April 2018 Accepted: 18 June 2018 Published: 10 July 2018

Citation:

Romo JA, Pierce CG, Esqueda M, Hung $C-Y$, Saville SP and

Lopez-Ribot JL (2018) In Vitro Characterization of a Biaryl Amide Anti-virulence Compound Targeting Candida albicans Filamentation and Biofilm Formation.

Front. Cell. Infect. Microbiol. 8:227.

doi: 10.3389/fcimb.2018.00227

\author{
Jesus A. Romo ${ }^{1}$, Christopher G. Pierce ${ }^{2}$, Marisol Esqueda ${ }^{1}$, Chiung-Yu Hung ${ }^{1}$, \\ Stephen. P. Saville ${ }^{1}$ and Jose L. Lopez-Ribot ${ }^{1 *}$
}

${ }^{1}$ Department of Biology, South Texas Center for Emerging Infectious Diseases, The University of Texas at San Antonio, San Antonio, TX, United States, ${ }^{2}$ Department of Biology, University of the Incarnate Word, San Antonio, TX, United States

We have previously identified a small molecule compound, $\mathrm{N}$-[3-(allyloxy)-phenyl]-4-methoxybenzamide (9029936), that exerts potent inhibitory activity against filamentation and biofilm formation by the Candida albicans SC5314 strain and represents a lead candidate for the development of anti-virulence approaches against C. albicans infections. Here we present data from a series of experiments to further characterize its in vitro activity and drug-like characteristics. We demonstrate the activity of this compound against a panel of $C$. albicans clinical isolates, including several displaying resistance to current antifungals; as well as against a set of $C$. albicans gain of function strains in key transcriptional regulators of antifungal drug resistance. The compound also inhibits filamentation and biofilm formation in the closely related species C. dubliniensis, but not C. glabrata or C. tropicalis. Combinatorial studies reveal the potential of compound 9029936 to be used together with currently available conventional antifungals. Results of serial passage experiments indicate that repeated exposure to this compound does not elicit resistance. Viability staining of $C$. albicans in the presence of high concentrations of compound 9029936 confirms that the compound is not toxic to fungal cells, and cytological staining using image flow cytometry analysis reveals that treatment with the lead compound affects hyphal length, with additional effects on cell wall and integrity of the membrane system. In vitro pharmacological profiling provides further evidence that the lead compound displays a safe profile, underscoring its excellent "drug-like" characteristics. Altogether these results confirm the potential of this compound to be further developed as a true anti-virulence agent for the treatment of $C$. albicans infections, including those refractory to treatment with conventional antifungal agents.

Keywords: Candida albicans, candidiasis, biofilms, filamentation, anti-virulence drugs

\section{INTRODUCTION}

Candida albicans is an opportunistic pathogenic fungus commonly found in the majority of individuals as a commensal of the gastrointestinal and genitourinary tracts, as well as the skin, where it is controlled by host and microbial interactions (Romani et al., 2003, 2015; Kadosh and Lopez-Ribot, 2013; Salvatori et al., 2016). In healthy individuals, C. albicans is usually harmless, 
although it can develop into non-life threatening infections (i.e., vulvovaginal candidiasis) after heavy antibiotic treatment (Fidel, 1998). Moreover, an expanding number of immune-, as well as medically-compromised individuals such as those with catheters, stents, and prosthetics, are at risk of life threatening infections such as disseminated candidiasis (Brown et al., 2012). Although antifungal agents are available and can sometimes be utilized successfully, overall therapeutic options for the treatment of candidiasis are limited, and together with the emergence of resistance and the toxicity displayed by some of the presently used antifungal therapies, highlight the urgency in the search for alternative approaches for the therapy of candidiasis (Pierce and Lopez-Ribot, 2013; Pierce et al., 2013, 2015b; Perfect, 2017). We have recently described the identification of a series of small molecule compounds that can serve as the basis for the development of novel anti-virulence strategies for the treatment of C. albicans infections (Romo et al., 2017). Our leading candidate, compound 9029936, displays potent inhibitory activity against two of the major virulence traits of C. albicans, filamentation and biofilm formation, both in vitro and in clinically-relevant murine models of candidiasis (Romo et al., 2017). This anti-virulence mode of action is radically different to that displayed by current antifungals that target fungal growth (Odds et al., 2003). As such, it may represent the basis for effective prophylactic and therapeutic options for the management of candidiasis, including those infections that are recalcitrant to conventional antifungal therapy (Gauwerky et al., 2009). Currently, there are no anti-virulence molecules approved to treat fungal infections although several promising candidates have been reported in the literature targeting $C$. albicans filamentation and biofilm formation, the two main virulence factors utilized for pathogenicity (Shareck and Belhumeur, 2011; Fazly et al., 2013; Pierce et al., 2015a). In the case of bacterial pathogens, anti-virulence approaches are well established as an alternative for antibiotic development and is an area of intensive research (Clatworthy et al., 2007). This further supports the potential therapeutic uses for anti-virulence strategies, which could be added to the alarmingly limited list of antifungal agents.

Here we present a series of experiments with results confirming the true anti-virulence nature of our leading compound and demonstrating its activity against different C. albicans clinical isolates, including those displaying multiple underlying mechanisms of antifungal drug resistance, as well as against C. dubliniensis. Altogether, our results reaffirm the promise of this leading compound for the development of novel anti-virulence approaches against candidiasis.

\section{MATERIALS AND METHODS \\ Strains and Culture Conditions}

The wild type C. albicans strain SC5314 was utilized for the majority of studies. In addition, we used a series of C. albicans clinical isolates obtained from HIV-infected patients with oropharyngeal candidiasis (White, 1997a,b), including sets of matched susceptible and resistant isolates for which molecular mechanisms of azole resistance have been previously characterized (White, 1997a,b; Perea et al., 2001); as well as a set of genetically-engineered C. albicans "gain of function" strains in key transcriptional regulators of azole resistance (a kind gift from David Rogers) (Schubert et al., 2008; Flowers et al., 2012). We also use representative clinical isolates of several nonalbicans Candida species, including C. dubliniensis isolate 121762, C. tropicalis isolate 11-2332, and C. glabrata isolate 13-1239 (obtained from the Fungus Testing Laboratory at UTHSCSA). For all strains, cell stocks were stored at $-80^{\circ} \mathrm{C}$ and propagated by streaking onto yeast extract peptone dextrose (YPD) agar plates $[1 \%(\mathrm{wt} / \mathrm{vol})$ yeast extract, $2 \%(\mathrm{wt} / \mathrm{vol})$ peptone, $2 \%$ (wt/vol) dextrose, and $1.5 \%$ agar], and incubated overnight at $30^{\circ} \mathrm{C}$. From these, a loopful of cells was inoculated into flasks $(150 \mathrm{ml})$ containing $25 \mathrm{ml}$ of YPD liquid media in an orbital shaker at 180 r.p.m. and grown overnight for $14-16 \mathrm{~h}$ at $30^{\circ} \mathrm{C}$. Under these conditions, Candida grows as a budding yeast.

\section{Drugs}

Milligram quantities of the lead small molecule compound 9029936 and its structurally related analog 7977044 (with similar activity as described previously) (Romo et al., 2017) were obtained from stock compounds available for hit resupply from Chembridge Corporation (San Diego, CA). A stock solution of fluconazole (Hospira, Lake Forest, IL) prepared in sodium chloride for injection at $2 \mathrm{mg} / \mathrm{ml}$ was obtained and stored at $4^{\circ} \mathrm{C}$ until used. Amphotericin B was obtained in solution at $250 \mu \mathrm{g} / \mathrm{ml}$ (Gibco Life Technologies, Grand Island, NY) and stored at $-20^{\circ} \mathrm{C}$ until used. Caspofungin (Merck \& Co., Inc., Whitehouse Station, NJ) was obtained as a powder and was stored at $4^{\circ} \mathrm{C}$; a stock solution was prepared in PBS at $2 \mathrm{mg} / \mathrm{ml}$ the same day before its addition to well plates.

\section{Inhibitory Effect on Candida Biofilm Formation}

These assays used the 96-well flat bottom plate model of C. albicans biofilm formation originally developed by our group (Ramage et al., 2001b; Pierce et al., 2008, 2010). For inhibition of biofilm formation, serial 2-fold dilutions (ranging from 20 to $0.039 \mu \mathrm{M}$ ) of investigational compounds were added to the wells of 96-well flat bottom microtiter plates before seeding with aliquots of fungal cells in RPMI-1640 medium supplemented with L-glutamine (Corning, Corning, NY) and buffered with $165 \mathrm{mM}$ morpholinepropanesulfonic acid (Sigma, St. Louis, MO) $\left(100 \mu \mathrm{L} /\right.$ well of a $1 \times 10^{6}$ cells $/ \mathrm{ml}$ solution). For $C$. dubliniensis, additional experiments were performed in which biofilms of C. dubliniensis clinical isolate 12-1762 were grown in N-Acetyl Glucosamine (GlcNAc) (Shepherd et al., 1980; Hubbard et al., 1985), or Spider media (Liu et al., 1994) using serial 2 -fold dilutions ranging from 40 to $0.078 \mu \mathrm{M}$. Appropriate positive (absence of drug, to allow for uninterrupted biofilm formation) and negative (no cells, to monitor contamination and to be able to calculate percent inhibition) controls were added. Each compound was assayed at least in duplicate plates (biological replicates), with 4-8 technical replicates per plate. The plates were incubated at $37^{\circ} \mathrm{C}$ for $24 \mathrm{~h}$ to allow for biofilm formation. After the incubation period the plates were washed twice with $200 \mu \mathrm{L} /$ well of PBS and biofilm inhibition was 
measured using the 2,3-Bis-(2-Methoxy-4-Nitro-5-Sulfophenyl)$2 \mathrm{H}$-Tetrazolium-5-Carboxanilide (XTT) colorimetric assay as previously described by our group (Ramage et al., 2001b; Pierce et al., 2008, 2010). The $\mathrm{IC}_{50}$ value, defined as the concentration of each compound leading to $50 \%$ inhibition of biofilm formation, was calculated from the results of these assays, using Prism (GraphPad Software Inc., San Diego, CA).

A similar series of experiments was performed in which biofilms were stained with crystal violet to assess biofilm biomass as previously described (O'Toole, 2011). Briefly, after the last incubation, plates were washed twice with PBS and each well was treated with $100 \mu \mathrm{L}$ of methanol for $20 \mathrm{~min}$ for fixation. Methanol was removed and plates allowed to dry. Adherent biofilms were then stained for $10 \mathrm{~min}$ with $150 \mu \mathrm{L}$ of $3 \%(\mathrm{w} / \mathrm{v})$ crystal violet. After crystal violet was removed and plates were allowed to dry, they were washed thrice with $200 \mu \mathrm{L}$ of distilled water. For each well, $100 \mu \mathrm{L}$ of $33 \%$ glacial acetic acid was used to dissolve the dye (after microscopy). Glacial acetic acid was left in the wells for $5 \mathrm{~min}$ while shaking slowly. Solution was then transferred to a new microtiter plate for $\mathrm{OD}_{550}$ measurement to calculate the extent of biofilm inhibition as compared to untreated controls. For microscopy, stained samples were directly observed on the 96-well plate using a 40x objective in an inverted system microscope (Westover Scientific, Mill Creek, WA) equipped for photography. The images were processed for display using Micron software (Westover Scientific).

\section{Inhibition of Filamentation Under Different Growth Media Conditions}

The ability of compound 9029936 to inhibit C. dubliniensis filamentation was examined under different growing conditions as previously described (Romo et al., 2017). Media selected include YPD, YPD plus 10\% fetal bovine serum (FBS), RPMI 1640, Lee et al. (1975), Spider (Liu et al., 1994), and N-Acetyl Glucosamine (GlcNAc) (Shepherd et al., 1980; Hubbard et al., 1985).

\section{Invasion Assay}

For invasion assays, compound 9029936 was added to half of the plate at a concentration of $5 \mu \mathrm{M}$. Plates were then placed at $30^{\circ} \mathrm{C}$ to allow for compound diffusion. A 1:1,000 dilution of $C$. dubliniensis isolate $12-1762$ was made from a $2 \times 10^{6}$ cells $/ \mathrm{ml}$ solution and streaked on to a quadrant with compound 9029936 and on a quadrant without compound. Plates were incubated at $37^{\circ} \mathrm{C}$ for $5-7$ days. Images were taken before and after rinsing plate with water.

\section{Checkerboard Assays for Drug Combinations of the Lead Compounds With Clinically Used Antifungal Drugs Against C. albicans Biofilms}

The effect of the lead compound 9029936 in combination with three commonly used antifungal drugs (fluconazole, amphotericin B, and caspofungin) was determined against planktonic cells, biofilm formation, and preformed biofilms. Briefly, compound 9029936 and antifungals were diluted using a checkerboard method. Rows A-G of the 96 well plate contained serial 2-fold dilutions of the lead compound, ranging from 40 to $0.156 \mu \mathrm{M}$, and row $\mathrm{H}$ contained no compound. Columns 19 of the microtiter plate contained serial 2-fold dilutions of either fluconazole $(16-0.25 \mu \mathrm{g} / \mathrm{mL})$, amphotericin B $(8-0.125 \mu \mathrm{g} / \mathrm{mL})$, or caspofungin $(16-0.25 \mu \mathrm{g} / \mathrm{mL})$; while column 10 contained no antifungal drug. Column 11 of the microtiter plate contained no test compound or drug to serve as a positive control for planktonic growth or biofilm formation and column 12 contained only media to serve as a background control. To assess the effect of the combination therapy on biofilm formation, columns $1-11$ of the microtiter plates were seeded with $100 \mu \mathrm{l}$ of C. albicans SC5314 at a concentration of $1 \times 10^{6}$ cells $/ \mathrm{ml}$ in RPMI containing the appropriate concentrations of test compound and antifungal drugs, and incubated for $24 \mathrm{~h}$ at $37^{\circ} \mathrm{C}$. Nonadherent cells were removed by washing twice with sterile PBS and inhibition of biofilm formation was determined using the XTT reduction assay. To assess the effect on preformed biofilms, columns $1-11$ of microtiter plates were seeded with $100 \mu \mathrm{l}$ of C. albicans SC5314 at a concentration of $1 \times 10^{6}$ cells $/ \mathrm{ml}$ in RPMI and plates were incubated for $24 \mathrm{~h}$ at $37^{\circ} \mathrm{C}$ to allow for mature biofilms to form. The biofilms were washed twice with sterile PBS and $100 \mu \mathrm{l}$ fresh RPMI media containing the appropriate dilutions of test compound and antifungal drug were added to the wells and biofilms were incubated for an additional $24 \mathrm{~h}$ prior to the final washing with sterile PBS and quantification using the XTT reduction assay. Percent biofilm inhibition was determined for each combination of compound and drug. To assess the effect of the combination therapy on planktonic growth, columns 111 of the round bottom microtiter plates were seeded with 200 $\mu \mathrm{l}$ of C. albicans SC5314 at a concentration of $0.5 \times 10^{3}$ cells $/ \mathrm{ml}$ in RPMI-1640 containing the appropriate concentrations of test compound and antifungal drugs then incubated for $24 \mathrm{~h}$ at $30^{\circ} \mathrm{C}$. Effect on planktonic growth was determined using the $\mathrm{OD}_{600}$ readings.

In all cases, using the calculated minimum inhibitory concentration for each compound and antifungal alone and the combination of the compound with antifungal, the fractional inhibitory concentration (FIC) for the pair was used to determine and used to detect if synergism, indifference, or antagonism was present when biofilms were treated with a combination of compounds and antifungal drugs. The value of the $\sum$ FIC index is used to interpret the nature of the interactions: synergism $\leq 0.5$, indifference $>0.5$ to $\leq 4$, antagonism $>4$ (Hindler, 1983, 1994, 1995; Jorgensen et al., 1994).

\section{Serial Passage Experiments for Induction of Resistance}

Two individual populations of $C$. albicans were founded from a single colony of $C$. albicans SC5314. One culture was grown in YPD medium at $37^{\circ} \mathrm{C}$ in the absence of serum (non-filamenting inducing conditions), the other was grown in RPMI- 1640 at $37^{\circ} \mathrm{C}$ (filament-inducing conditions). For each condition, cultures were grown without any treatment (as control) or in the presence of $5 \mu \mathrm{M}$ of 9029936 compound, a concentration previously determined to inhibit biofilm formation and filamentation 
without affecting cell growth (Romo et al., 2017). Cultures were placed in orbital shakers and every day $10 \mu \mathrm{l}$ from each culture were serially transferred into $3 \mathrm{ml}$ of the corresponding fresh medium, YPD or RPMI-1640 in the presence or absence of $5 \mu \mathrm{M}$ of the leading compound. These transfers continued daily for 56 days, maintaining the concentration of 9029936 at $5 \mu \mathrm{M}$. After daily transfers, population samples were stored in $1 \mathrm{ml}$ of $40 \%$ (vol/vol) glycerol at $-80^{\circ} \mathrm{C}$. To assess for the development of resistance, cultures grown in the presence of the small molecule compound were monitored for the presence/absence of hyphae before daily transfers microscopically (not shown). Cells from the stored populations were streaked, grown overnight, and used to seed the wells of 96-well microtiter plates in the presence of compound 9029936 at concentrations ranging from 40 to $0.078 \mu \mathrm{M}$ in RPMI and incubated at $37^{\circ} \mathrm{C}$ for $24 \mathrm{~h}$ to assess inhibitory activity against biofilm formation. For filamentation studies, cells from stored populations were streaked, grown overnight, and used to seed the wells of 96-well microtiter round bottom plates in the presence of compound 9029936 at concentrations ranging from 40 to $0.078 \mu \mathrm{M}$ in YPD plus $10 \% \mathrm{FBS}$ and incubated at $37^{\circ} \mathrm{C}$ for $6 \mathrm{~h}$ to assess the activity of compound 9029936 against filamentation. Microscopy was performed using differential interference contrast (DIC) on an Axio Observer D1 inverted microscope (Carl Zeiss, Thornwood, NY) equipped for photography.

\section{Cell Viability Staining}

The effect of compound 9029936 on C. albicans and C. dubliniensis cell viability was assessed using the viability staining protocol and kit (Invitrogen, Carlsbad, CA). Briefly, fungal cells were grown in the presence of compound 9029936 at varying concentrations $(2.5,5,10,20$, and $40 \mu \mathrm{M})$ in RPMI and incubated at $37^{\circ} \mathrm{C}$ for $24 \mathrm{~h}$ while shaking. After incubation cells were washed twice with $\mathrm{PBS}$ and a 1:1,000 dilution was stained with $10 \mu \mathrm{M}$ of FUN-1 for $1 \mathrm{~h}$ at $30^{\circ} \mathrm{C}$ in the dark. Cells were then spun at $5,000 \mathrm{rpm}$ for $5 \mathrm{~min}$ and FUN-1 was removed. Cells were then resuspended in $40 \mu \mathrm{L}$ of Calcofluor white (CFW) at a concentration of $25 \mu \mathrm{M}$ for $10 \mathrm{~min}$ at room temperature. Fluorescent and DIC microscopy was performed using an Axio Observer D1 inverted microscope (Carl Zeiss) equipped for photography.

\section{Examination of Fungal Cellular States Using Imaging Flow Cytometry}

A 1:30 dilution of an overnight culture of C. albicans SC5314 was used to inoculate a 96-well round bottom microtiter plate containing compound 9029936 at a concentration of $10 \mu \mathrm{M}$ in $100 \mu \mathrm{L}$ of RPMI-1640 medium and incubated for $6 \mathrm{~h}$ at $37^{\circ} \mathrm{C}$ with $5 \% \mathrm{CO}_{2}$. After incubation, cells were washed twice with PBS, followed by incubation with a solution containing $2.5 \mu \mathrm{g} / \mathrm{ml}$ FM4-64 FX membrane staining dye (Thermo-Fisher Scientific, Waltham, MA) and $0.4 \mu \mathrm{g} / \mathrm{ml}$ Calcofluor white (CFW) in a modified phosphate buffer saline, $\mathrm{pH} 8.0$ for $30 \mathrm{~min}$ at $37^{\circ} \mathrm{C}$. Following staining, wells were washed and re-suspended in 30 $\mu \mathrm{L}$ of $2 \%$ paraformaldehyde solution. Samples were analyzed with an ImageStreamX MKII (Millipore, Burlington, MA) image flow cytometer with a $7-\mu \mathrm{m}$ core at low flow rate and high sensitivity using INSPIRE software. Fluorochromes were excited with 405, 561, and $785 \mathrm{~nm}$ lasers and image data was collected through a $60 \times$ objective in appropriate channels. Single-color reference samples for each fluorochrome were generated by inclusion of cells that are incubated with each fluorochrome separately. Images were analyzed using IDEAS ${ }^{\circledR}$ software version 6.2 (Millipore, Burlington, MA). A compensation matrix was built with the data from single-color reference samples to allow removal of spectral spillover to adjacent channels from each detection channel. Single-cell images were first gated on the focused cells with a size (area) range between 50 and 200 pixels $\left(\sim 15-60 \mu \mathrm{m}^{2}\right)$. A dot plot of bright field area vs. aspect ratio (width/length) was used to distinguish yeast, elongated cells, and hyphae subpopulations that have aspect ratios $(r)$ ranging from $r>0.75,0.75 \geq r \geq 0.38$, and $r<0.38$, respectively. Cellular states including cell length, CFW, and FM4-64 binding indexes were measured and plotted. To accommodate the total CFW and FM464 , intensity increased when cell size enlarged during yeast-hypha transition, the binding indexes were defined as the ratios of the sum of the pixel intensities of CFW and FM4-64 in the cell masks divided by the cell length (intensity/length).

\section{Hydroxyurea Genotoxic Stress Assay}

Hydroxyurea assays for genotoxic stress were performed as previously described (Fazly et al., 2013). Briefly, C. albicans SC5314 cells from an overnight culture were washed twice with PBS and a 1:30 dilution was used to seed a 96-well round bottom microtiter plate containing compound 9029936 (ranging from 40 to $0.078 \mu \mathrm{M}$ ) as well as hydroxyurea (HU) at a concentration of $100 \mu \mathrm{M}$ (concentration shown to induce filamentation). Positive (cells in the presence of compound 9029936 only) and negative (cells in the presence of $100 \mu \mathrm{M}$ hydroxyurea only) controls were included. Plates were incubated at $37^{\circ} \mathrm{C}$ for $24 \mathrm{~h}$. Microscopy was performed using DIC on an Axio Observer D1 inverted microscope (Carl Zeiss) equipped for photography.

\section{Eurofin Cerep Safetyscreen 44 Panel for in Vitro Pharmacological Profiling and Detection of Off-Target Effects}

For pharmacological profiling and determination of off target effects, the leading 9029936 compound was screened at a $10 \mu \mathrm{M}$ concentration in duplicate for potential to bind to a broad panel of receptors, enzymes, and ion channels in a commercial screen (SafetyScreen 44, Eurofins Cerep-Panlabs, France). Details and experimental conditions for these assays can be found online at www.cerep.fr. For a list of specific assays please refer to Figure 8.

\section{RESULTS}

\section{Activity of Compound 9029936 Against Azole Resistant Clinical Isolates and Gain-of-Function Strains}

We performed susceptibility testing of compound 9029936 against a number of clinical isolates recovered form HIVinfected patients with oropharyngeal candidiasis, including several isolates that are resistant to treatment with conventional antifungals (White, 1997a,b). These susceptibility assays were 
conducted for biofilm inhibition. In addition, we also examined the activity of our leading compound against several gainof-function strains, which are laboratory generated strains overexpressing key regulators of the ergosterol pathway and drug resistance efflux pumps (Schubert et al., 2008; Flowers et al., 2012); more specifically these included a gain-of-function strain in UPC2, leading to overexpression of ERG11, the gene encoding the target enzyme of azole antifungals, as well as gain-of-function strains in MRR1 and TAC1, leading to overexpression of $M D R$ and $C D R$ genes respectively, encoding a major facilitator and an $\mathrm{ABC}$ transporter involved in antifungal drug resistance (Schubert et al., 2008; Flowers et al., 2012). Table 1 contains information on each of these strains as well as the $\mathrm{IC}_{50}$ values obtained from the biofilm inhibition assays. As in Table 1 , the $\mathrm{IC}_{50}$ values obtained using each of the strains and isolates were mostly comparable (although slightly elevated for strains ScMRR1R34A, ScTAC1R34A, 2440, and 3731) to those values determined against the laboratory strain SC5314, therefore validating the activity of compound 9029936 against multiple C. albicans strains with decreased susceptibility against conventional antifungals, including both clinical isolates and laboratory-generated strains.

\section{Activity of Compound 9029936 and 7977044 Against Non-albicans Candida Species}

We have previously described that compounds 9029936 and its analog 7977044 were able to inhibit biofilm formation in C. albicans (Romo et al., 2017), most likely as a direct consequence of their inhibitory effects on filamentation, since in C. albicans these two processes are inextricably linked (Ramage et al., 2001c, 2005; Lopez-Ribot, 2005; Pierce et al., 2014). A true anti-virulence agent should, in theory, be highly specific to the organism or species that employs that virulence factor (Clatworthy et al., 2007; Rasko and Sperandio, 2010; Pierce et al., 2015a). Not all Candida species are capable of undergoing the yeast to hyphae transition, and one would expect that our leading compounds may display different levels of activity against different Candida species depending on their intrinsic ability to filament. Moreover, different Candida spp. also display varying abilities to form biofilms (Gilfillan et al., 1998; Ramage et al., 2001a; Jabra-Rizk et al., 2004; Silva et al., 2012; Brunke and Hube, 2013; Sardi et al., 2013), which may or not be related to their ability to filament. Thus, in an initial set of experiments we examined the biofilm inhibitory activity of the two leading compounds from this series against other non-albicans Candida species, the species selected for these experiments were ones known to form biofilms associated with filamentation (C. tropicalis and C. dubliniensis), as well as $C$. glabrata, which is capable of forming biofilms independent of filamentation (Silva et al., 2012; Brunke and Hube, 2013; d'enfert and Janbon, 2016). It is important to note that these nonalbicans species in general are unable to form robust and durable biofilms like those of C. albicans. As shown in Figure 1, the only species against which the compounds displayed biofilminhibitory activity was C. dubliniensis. These results are not surprising, since C. dubliniensis is the closest related organism to
C. albicans (Gilfillan et al., 1998; Sullivan and Coleman, 1998). Both C. glabrata and C. tropicalis were able to form biofilms uninhibited by the presence of the compounds. In C. glabrata, this is probably due to the inability to filament, which further underscores the specificity of the compounds and their antivirulence nature. In the case of $C$. tropicalis, although presence of filamentous forms is observed in biofilms formed by this species, in general the extent of filamentation is much lower than in the case of C. albicans, and even C. dubliniensis (Silva et al., 2012; Lackey et al., 2013; Zhang et al., 2016), and thereby biofilm formation in this species overall may not depend solely on its ability to filament. Based on these results, we decided to study the activity of our lead compound 9029936 against C. dubliniensis filamentation and biofilm formation in more detail. Similar to its close relative $C$. albicans, these represent the two main virulence factors that are inherently linked to $C$. dubliniensis pathogenesis (Ramage et al., 2001a).

\section{Effects of Compound 9029936 on C. dubliniensis: Inhibition of Agar Invasion, Filamentation, and Biofilm Formation Under Multiple Environmental Conditions}

As shown previously, compound 9029936 displayed potent filamentation inhibition against C. albicans (Romo et al., 2017). We also concluded that the compound displayed activity against $C$. dubliniensis in the biofilm inhibition assay (Figure 1). Therefore, we hypothesized that the similar activity seen against $C$. dubliniensis is due to its close relatedness to C. albicans (Gilfillan et al., 1998; Sullivan and Coleman, 1998; Sullivan et al., 2005; McManus et al., 2008; Citiulo et al., 2009; Spiering et al., 2010). To further characterize this activity, we conducted an agar invasion assay as previously described (Romo et al., 2017). Briefly, C. dubliniensis cells from an overnight culture were streaked on to a YPD agar plate lacking or containing compound 9029936 at $5 \mu \mathrm{M}$ concentrations and incubated at $37^{\circ} \mathrm{C}$ for $5-7$ days. As expected, the untreated $C$. dubliniensis invaded the agar, while compound 9029936 inhibited filamentation and agar invasion (Figure 2A). Overall, these results indicate that similarly to the activity displayed against C. albicans, compound 9029936 strongly inhibited filamentation and agar invasion by $C$. dubliniensis.

To further characterize the filamentation inhibitory activity of compound 9029936 against $C$. dubliniensis, cells were grown under strong filament inducing conditions in the presence or absence of compound 9029936 at $5 \mu \mathrm{M}$ concentrations and incubated at $37^{\circ} \mathrm{C}$ for $48 \mathrm{~h}$. The conditions tested included YPD, YPD plus 10\% FBS, Lee's medium (Lee et al., 1975), RPMI 1640, GlcNAc (Shepherd et al., 1980; Hubbard et al., 1985), and Spider medium (Liu et al., 1994). C. dubliniensis is unable to filament as effectively as C. albicans (Moran et al., 2007; Stokes et al., 2007; Spiering et al., 2010), and therefore, induction of filamentation through multiple media conditions was required to identify a suitable environment in which to study its filamentation. As show in Figure 2B, C. dubliniensis was able to filament under all four conditions 
TABLE 1 | Biofilm inhibitory activity of compound 9029936 against C. albicans clinical isolates and gain-of-function strains.

\begin{tabular}{|c|c|c|c|}
\hline Strain/Isolate & Description & Overexpressed genes & $\begin{array}{c}\mathrm{IC}_{50} \text { (biofilm } \\
\text { inhibition) in } \mu \mathrm{M}\end{array}$ \\
\hline SC5314 & Wild-type laboratory strain & N/A & 1.875 \\
\hline TW1 & $\begin{array}{l}\text { Clinical isolate (matched susceptible isolate for } \\
\text { this series) }\end{array}$ & $\mathrm{N} / \mathrm{A}$ & 0.8022 \\
\hline TW2 & Clinical isolate (drug resistance observed) & MDR1 & 0.6031 \\
\hline TW17 & $\begin{array}{l}\text { Clinical isolate (multi drug resistance observed) } \\
\text { Point mutation: R467K }\end{array}$ & $C D R 1, M D R 1, E R G 11$ & 2.767 \\
\hline \multicolumn{4}{|c|}{ GAIN-OF-FUNCTION STRAINS OVEREXPRESSING REGULATORS OF AZOLE RESISTANCE } \\
\hline SCR (GOF Control) & $\begin{array}{l}\text { Wild-type strain background used to generate } \\
\text { gain-of-function strains }\end{array}$ & N/A & 1.814 \\
\hline ScUPC2R14A & $\begin{array}{l}\text { Strain with homozygous activating mutation in } \\
\text { UPC2 (G648D) } \\
\text { (UPC2G648D_FRT/UPC2G648D_FRT }\end{array}$ & UPC2 and ERG11 & 1.569 \\
\hline ScTAC1R34A & $\begin{array}{l}\text { Strain with homozygous activating mutation in } \\
\text { TAC1 (6980E) } \\
\text { (TAC16980E_FRT/TAC16980E_FRT }\end{array}$ & TAC1, CDR1 and CDR2 & 4.400 \\
\hline \multicolumn{4}{|c|}{ FLUCONAZOLE RESISTANT CLINICAL ISOLATES } \\
\hline 4639 & F449S, T229A (Erg11p substitutions) & MDR1, CDR1 & 1.424 \\
\hline 4617 & F449S, T229A (Erg11p substitutions) & N/A & 0.9198 \\
\hline 6482 & $\begin{array}{l}\text { D116E, K128T, Y132H, } \\
\text { D278N, G464S, P230L } \\
\text { (Erg11p substitutions) }\end{array}$ & $\mathrm{N} / \mathrm{A}$ & 3.011 \\
\hline 2440 & V437I (Erg11p substitution) & MDR1, ERG11 & 5.645 \\
\hline
\end{tabular}

The $I C_{50}$ values were determined from dose-response experiments looking at the ability of the compound to inhibit biofilm formation by the different $C$. albicans strains.

tested, while the presence of compound 9029936 blocked this morphological transition. We note that in GlcNAc media, C. dubliniensis did not form true hyphae, but instead was able to undergo the morphological transition into pseudohyphal forms.

Since compound 9029936 was able to inhibit agar invasion (Figure 2A) as well as filamentation under several inducing conditions (Figure 2B), we posited that it would also be able to inhibit biofilm formation by $C$. dubliniensis in different growth media, besides the most common RPMI used in our initial experiments. Thus, C. dubliniensis biofilms were grown in 96well microtiter plates using either Spider (Shepherd et al., 1980; Hubbard et al., 1985; Liu et al., 1994) or GlcNAc (Shepherd et al., 1980; Hubbard et al., 1985) media. As seen in Figure 3, these conditions led to robust biofilm formation. However, the presence of compound 9029936 at concentrations as low as $5 \mu \mathrm{M}$ was able to prevent biofilm formation by this $C$. dubliniensis strain. From these experiments, the calculated $\mathrm{IC}_{50}$ values were 0.5582 and $1.264 \mu \mathrm{M}$ for both Spider and GlcNAc media, respectively, which are similar to those observed for C. albicans in regular RPMI medium.

\section{Drug Combination Assays With Compound 9029936 and Currently Used Antifungal Agents}

Although drug combinatorial therapies are common when treating viral and bacterial infections, they have not been thoroughly implemented in the clinic for the treatment of fungal infections (Baddley and Pappas, 2005; Spitzer et al., 2017). The anti-virulence nature of compound 9029936 makes it an ideal candidate for combinatorial therapy with currently used antifungals. In order to investigate the activity of combinations between our leading compound and current antifungals we performed checkerboard assays using the planktonic, biofilm inhibition, and pre-formed biofilm assays (Table 2). These assays allow for the calculation of the fractional inhibitory concentration index (FICI), which allows for the identification of synergistic, indifferent, or antagonistic interactions between the compounds in question (Hall et al., 1983; Hindler, 1983, 1994; Jorgensen et al., 1994). A FICI of 0.5 or less indicates synergy, while numbers $>0.5$ indicate indifference. Any number equal to or higher than 4 is indicative of antagonistic interactions (Hall et al., 1983; Hindler, 1983, 1994; Jorgensen et al., 1994). 


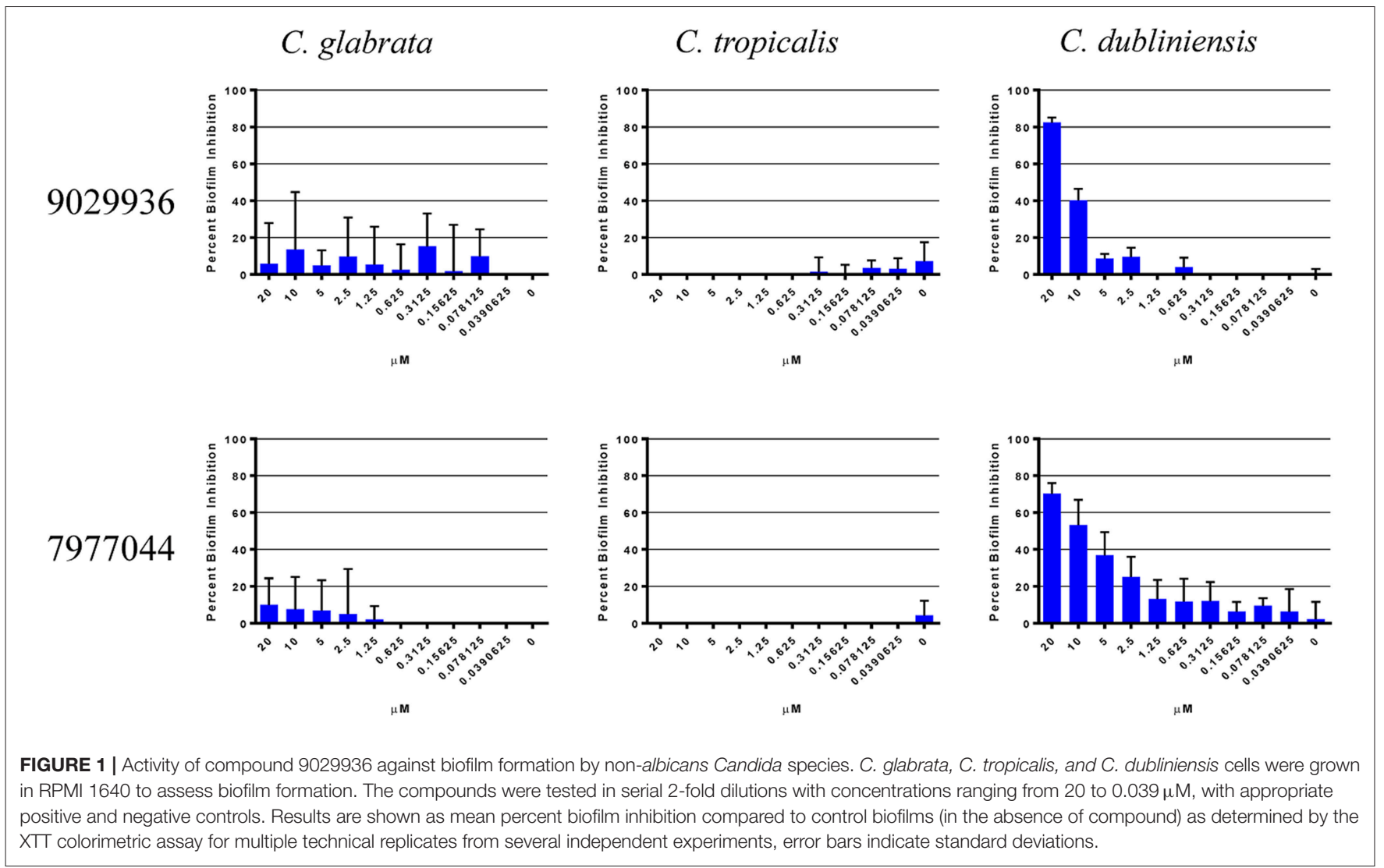

The antifungals used in these experiments were fluconazole, caspofungin, and amphotericin B, representatives of each of the three main classes of clinically-used antifungals, the azoles, the echinocandins, and the polyenes (Odds et al., 2003). Although we only observed synergistic activity for the combination of compound 9029936 and caspofungin against pre-formed biofilms, we observed indifference for all other combinations and conditions tested. In no instance we observed antagonism, suggesting that compound 9029936 could be potentially used in combination with currently used antifungal drugs. Similar results were obtained for compound 7977044 (data not shown).

\section{Serial Passage Experiments in the Presence of the Lead Compound to Assess the Potential for the Development of \\ Resistance}

As shown previously, compound 9029936 behaves as a true anti-virulence agent by inhibiting $C$. albicans filamentation without having any significant effect on growth (Romo et al., 2017). Indeed, the reason microorganisms develop resistance to a specific drug is because most drugs target components or processes vital for cell growth and survival (Blair et al., 2015; Hughes and Andersson, 2015; Fairlamb et al., 2016). It is this selective pressure that forces the microorganism to adapt and survive (Blair et al., 2015; Hughes and Andersson, 2015; Fairlamb et al., 2016). A true anti-virulence agent should in theory not induce (or should be able to delay) the development of resistance because it targets virulence factors (Clatworthy et al., 2007; Rasko and Sperandio, 2010; Ling et al., 2015), which in opportunistic pathogens such as C. albicans, are not necessary for cell growth and survival. In order to further validate compound 9029936 as a true anti-virulence agent, we performed assays to attempt to induce the development of resistance in C. albicans as previously described (Pierce et al., 2015a). Briefly, C. albicans was grown under filament inducing conditions in the presence or absence of $5 \mu \mathrm{M}$ of compound 9029936 and passaged every day into fresh media containing the compound at the same concentration for 8 weeks. Each day, an aliquot was collected and frozen for future studies. During this process samples were also checked microscopically to assess filamentation (untreated samples) or the lack of filamentation (treated samples). No filamentation was seen in the treated samples through the duration of these experiments. To test if resistance was developed to compound 9029936, each isolate was streaked, grown overnight, and used in filamentation assays (Figure 4A) as well as in biofilm formation assays (Figure 4B). All isolates were able to filament properly under filament inducing conditions when compound 9029936 was absent. In comparison, compound 9029936 at $5 \mu \mathrm{M}$ was able to inhibit filamentation under filament inducing conditions by all of the isolates, indicating that no resistance to the compound was developed under the conditions tested, even after several weeks of serial passages. Moreover, the isolates were tested using the biofilm inhibition assay to assess fold changes in $\mathrm{SMIC}_{50}$ (sessile 


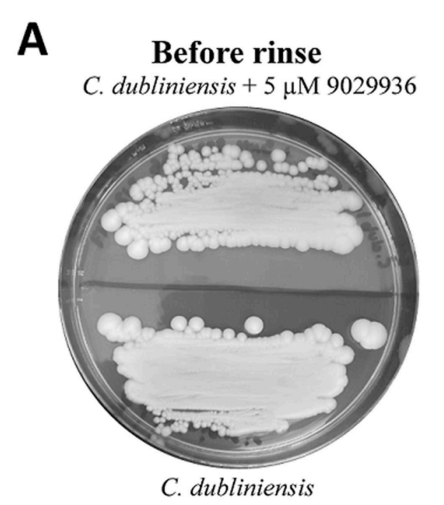

After rinse

C. dubliniensis $+5 \mu \mathrm{M} 9029936$

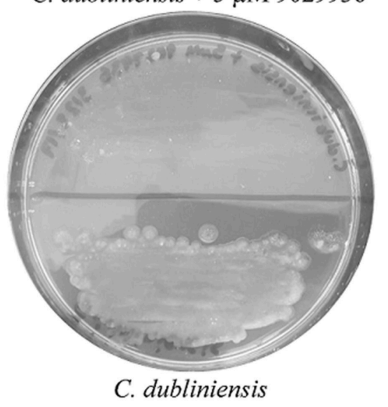

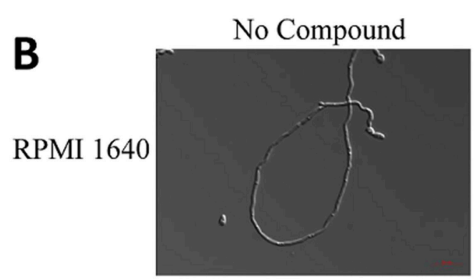
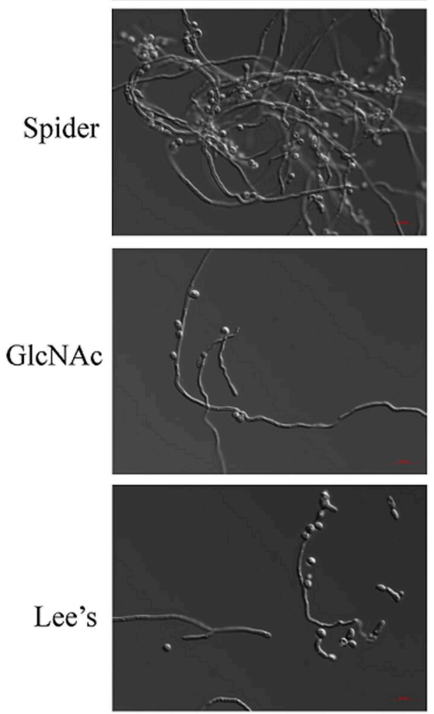

$5 \mu \mathrm{M} 9029936$
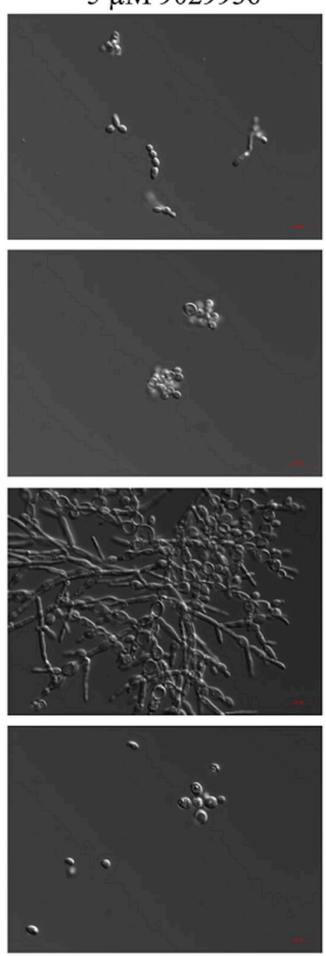

FIGURE 2 | Activity of compound 9029936 against C. dubliniensis in an agar invasion assay and filament stimulating conditions. (A) Compound 9029936 inhibits C. dubliniensis agar invasion. C. dubliniensis isolate 12-1762 cells were streaked on YPD plates with or without compound 9029936 at $5 \mu \mathrm{M}$ and the plates incubated at $37^{\circ} \mathrm{C}$ for 5 days. The plates were photographed prior to (top panel) and after (bottom panel) surface cells were removed by gentle washing under running water. In the presence of the compound cells grew mostly on the surface of the medium and were washed away, whereas cells grown in the absence of the compound had invaded the agar and remained after washing. (B) Inhibition of filamentation in different liquid media. Liquid cultures of $\mathrm{C}$. dubliniensis isolate $12-1762$ were grown in a variety of hypha-inducing media in the absence or presence of compound 9029936 at a concentration of $5 \mu \mathrm{M}$. Aliquots were taken from the different cultures at $6 \mathrm{~h}$ post-induction, visualized by DIC microscopy and photographed. Bars are $20 \mu \mathrm{m}$ in all panels.

minimum inhibitory concentration) (Figure 4B). As expected, all isolates displayed an $\mathrm{SMIC}_{50}$ comparable to that of day 0, with only a slight transitory increase detected for the isolate recovered on day 21. Overall, these results indicate that repeated exposure to the lead compound is highly unlikely to foster the emergence of resistance.

\section{The Lead Compound Is Not Toxic to Candida Cells at Concentrations Higher Than Those Needed to Inhibit Filamentation}

In order to further investigate the effects of compound 9029936 on cell growth and confirm its true anti-virulence activity, we performed viability staining of C. albicans SC5314 and C. dubliniensis isolate 12-1762 cells grown in the presence of different concentrations of the leading compound. Briefly, C. albicans SC5314 and C. dubliniensis isolate 12-1762 cells were grown at $37^{\circ} \mathrm{C}$ in the presence of compound 9029936 at concentrations ranging from 2.5 to $40 \mu \mathrm{M}$ for $24 \mathrm{~h}$. After incubation, cells were washed with PBS and stained with FUN1 (indicator of cell viability), followed by Calcofluor white (stains chitin in fungal cell walls), and visualized using a fluorescence microscope. If cells are viable, they will uptake FUN1 and the dye will concentrate in vesicles (red), while calcofluor white should stain all cells (blue). Figure 5 shows the images from the $40 \mu \mathrm{M}$ concentration samples of C. albicans SC5314 (Figure 5A) and C. dubliniensis isolate 12-1762 (Figure 5B). Another set of experiments was conducted at $30^{\circ} \mathrm{C}$, which yielded similar results (not shown). As seen in the Figure 5, compound 9029936 did not compromise cell viability even at $40 \mu \mathrm{M}$, the highest concentration tested, which is consistent with previous growth curve observations previously described by our group (Romo et al., 2017). Although fungistatic activity was observed at concentrations higher than $40 \mu \mathrm{M}$ (which are not physiologically relevant), no fungicidal activity was observed during our studies.

\section{The Drug-Treated C. albicans Cells Display Changes on Cell Size, Shape, and Integrity of Cell Wall and Membranous System}

In order to characterize the physiological effects of treatment with compound 9029936 on C. albicans cells, we utilized imaging flow cytometry to quantitatively measure cellular states. This technology combines the speed, sensitivity and phenotyping abilities of flow cytometry with the detailed imaging and 


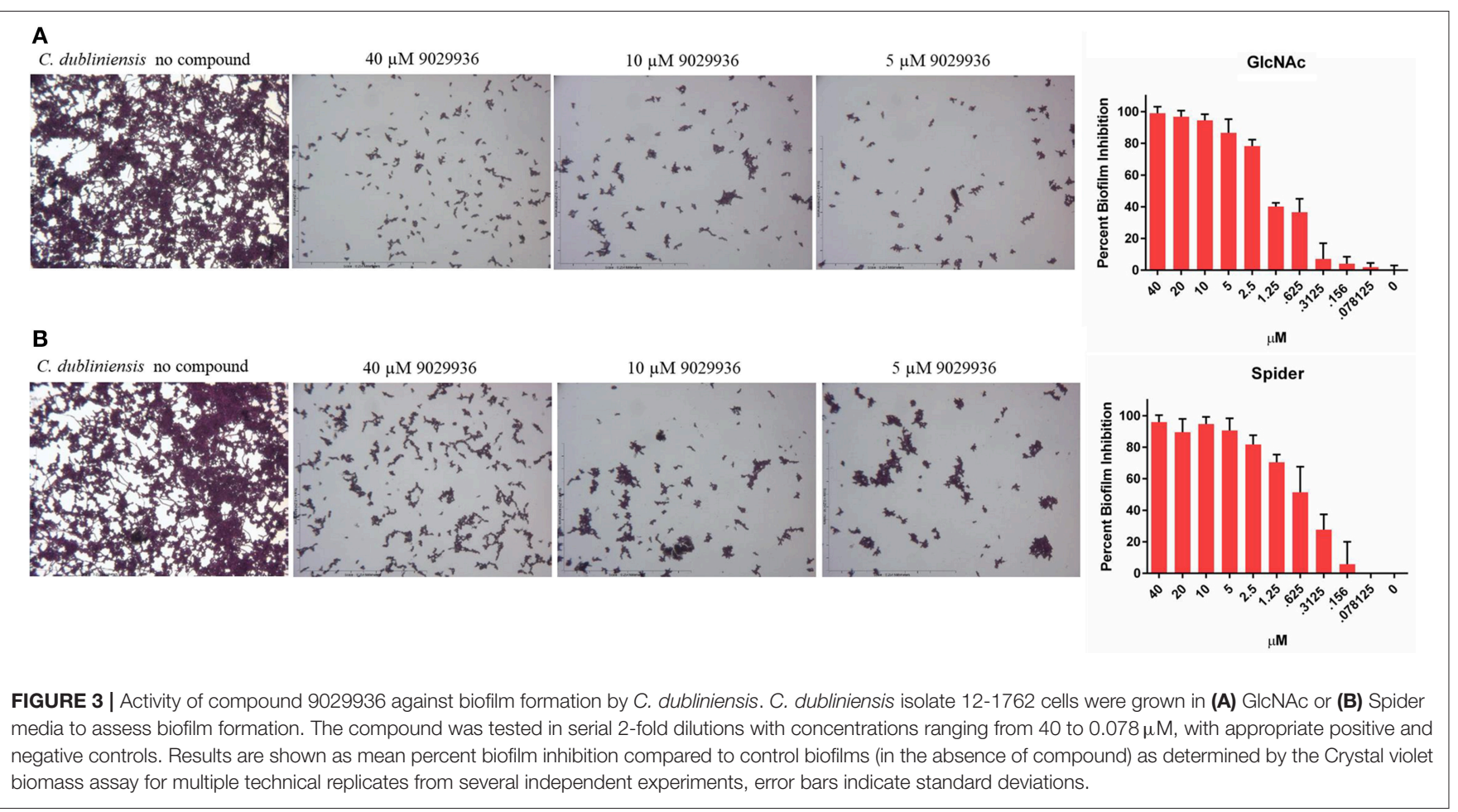

TABLE 2 | Fractional inhibitory concentration indices from drug combination assays.

\begin{tabular}{lccc}
\hline Drug combinations & Biofilm inhibition & Pre-formed biofilms & Planktonic \\
\hline $9029936+$ Fluconazole & Indifference $(\mathrm{FICl}=1.8)$ & Indifference $(\mathrm{FICl}=1.625)$ & Indifference $(\mathrm{FICl}=1.187)$ \\
$9029936+$ Amphotericin $B$ & Indifference $(\mathrm{FICl}=1.06)$ & Indifference $(\mathrm{FICl}=1.02)$ & Indifference $(\mathrm{FICl}=.6875)$ \\
$9029936+$ Caspofungin & Indifference $(\mathrm{FICl}=1.3125)$ & Synergy $(\mathrm{FICl}=.4082)$ & Indifference $(\mathrm{FICl}=1.328)$
\end{tabular}

Compound 9029936 was assessed in combination with conventional antifungal drugs to determine inhibitory effects on C. albicans strain SC5314 planktonic growth, biofilm formation, and against preformed biofilms.

functional insights of confocal microscopy, which allows for the visualization of effects on individual cells. Both control and treated cells were labeled with CFW and FM4-64 to assess the effects of the drug treatment on cell morphology, cell wall, and membrane integrity (Figure 6). As seen in Figure 6A, and consistent with its inhibitory effects on filamentation, C. albicans cells treated with compound 9029936 at $10 \mu \mathrm{M}$ for $6 \mathrm{~h}$ showed a much less elongated morphology as compared to untreated cells (Figures 6A-C). While the majority of control cells grew into hyphae (72.9 $\pm 0.1 \% ; 23.5 \pm 6.1$ in length), the treated cells only grew into elongated cells $(60.87 \pm 1.1 \% ; 13.7 \pm 3.3$ in length). The treated cells also had compromised cell walls and vacuolar membrane systems, indicated by a significant increase in CFW and FM4-64 binding indexes (gray vs. red) in Figure 6B. Representative images of hyphae from the control samples and elongated cells from the treated Candida cells are shown in Figure 6C. These results point to the possibility that compound 9029936 could affect proper cell wall and vacuolar membrane assembly. This could be partly due to the secondary effects of the filament inhibitory properties, which might be preventing the proper assembly or incorporation of cell wall and vacuole components.

\section{Compound 9029936 Inhibits Filamentation Induced Through the Genotoxic Stress Pathway}

Compound 9029936 was shown previously to inhibit C. albicans filamentation induced through all different environmental conditions tested (Romo et al., 2017). Most recently genotoxic stress has also been demonstrated to induce $C$. albicans filamentation through a damage response pathway (Fazly et al., 2013). In order to investigate the activity of compound 9029936 against filamentation induced through genotoxic stress, C. albicans was exposed to hydroxyurea at a concentration of $100 \mu \mathrm{M}$ for $24 \mathrm{~h}$ at $30^{\circ} \mathrm{C}$ (non-filament inducing conditions) in the presence or absence of compound 9029936 at concentrations ranging from 0.078 to $40 \mu \mathrm{M}$ (Figure 7). Hydroxyurea induced filamentation (through genotoxic stress) when it was present at $100 \mu \mathrm{M}$ in the absence of compound 9029936. In contrast, compound 9029936 was able to inhibit filamentation 

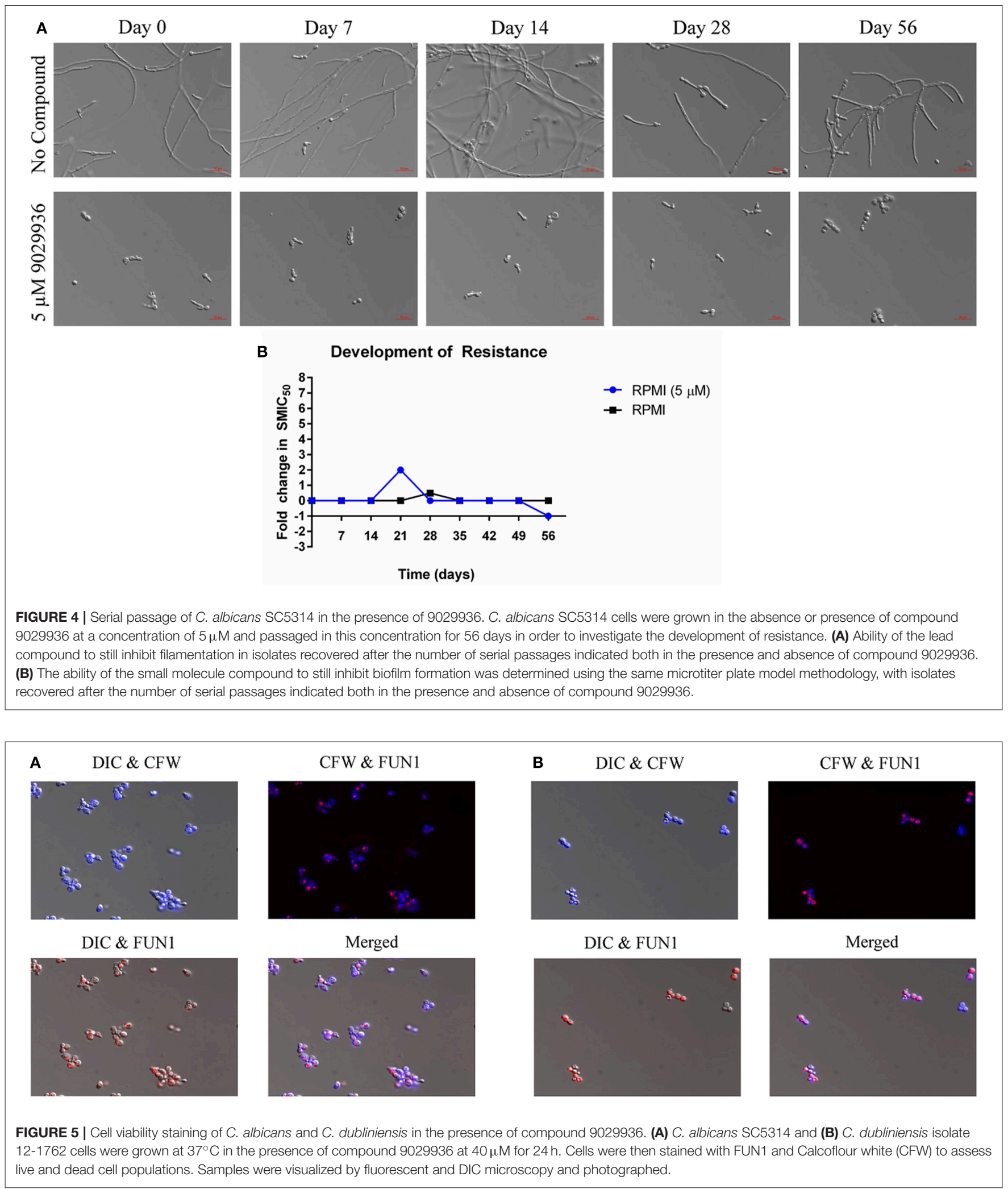

induced through this pathway at concentrations as low as $5 \mu \mathrm{M}$ (Figure 7). These results indicate that compound 9029936 prevented filamentation through less conventional pathways such as genotoxic stress, and extend the number of environmental conditions, impinging upon different regulatory pathways, under which it is capable to exert potent inhibitory 
A
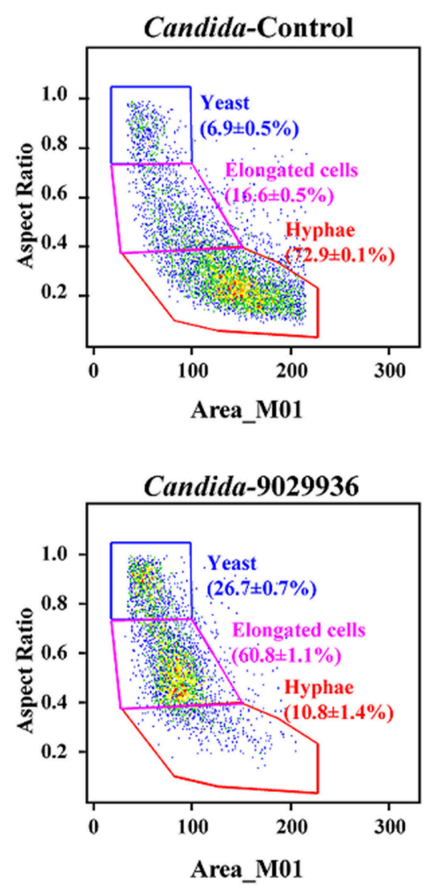

B
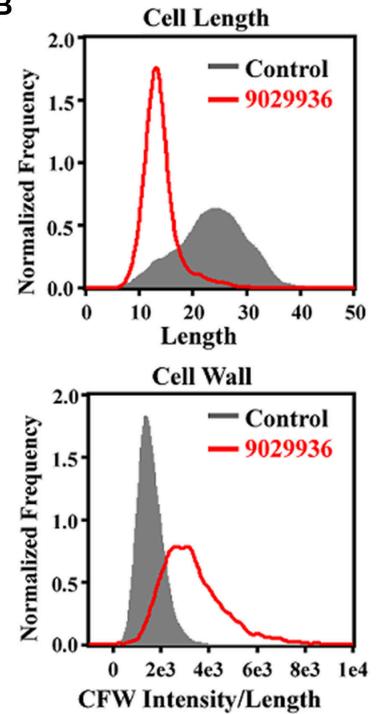

Membrane System

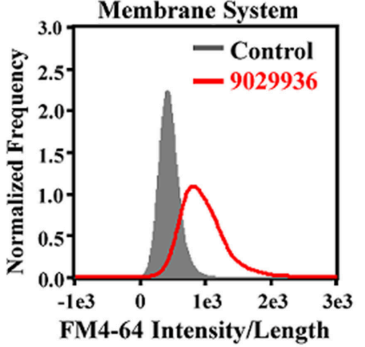

C

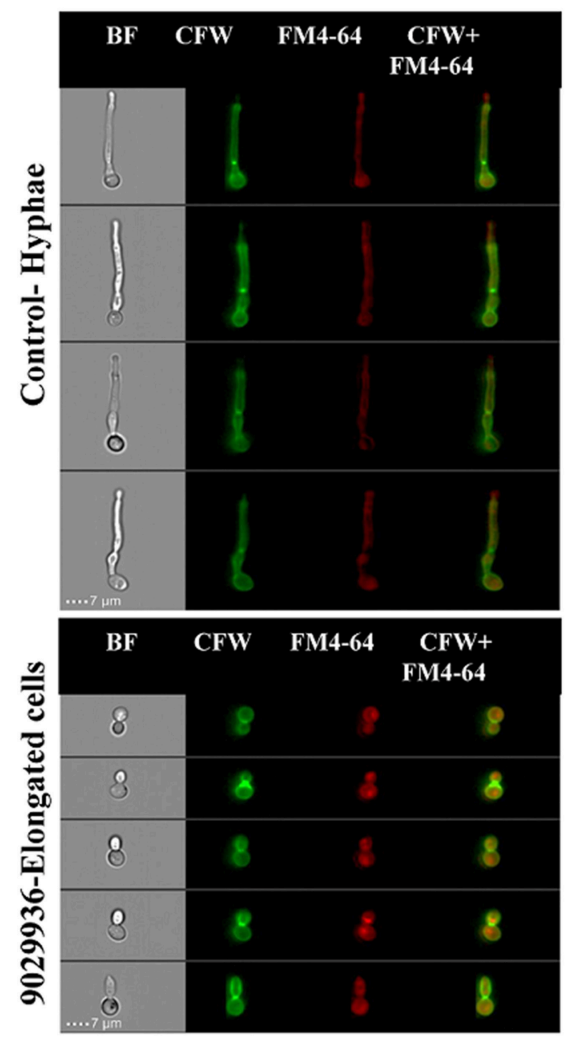

FIGURE 6 | Quantitative measurement of cellular states after treatment with compound 9029936 using image flow cytometry. C. albicans SC5314 cells were grown in the presence of compound 9029936 at a concentration of $10 \mu \mathrm{M}$ for $6 \mathrm{~h}$ compared to untreated control cells. Samples were then washed and stained with Calcofluor white (CFW) for cell wall and FM4-64 for hydrophobic membranes. (A) Cells were classified into 3 subpopulations based on their properties of area vs. aspect ratio. Results showed that the treated cells grew into elongated cells while majority of untreated yeast grew into hyphae ( $P<0.0001$; Student $T$-test). (B) Comparison of cellular states including cell length, CFW, and FM4-64 binding indexes for assessment of cell wall and membrane integrity between treated (red) and untreated control (gray) samples. (C) Representative images of control and treated cells showed drug effects on cell size, shape and integrity of cell wall and membrane system. Samples were acquired on an Amnis ImageStream Mark II imaging flow cytometer and analyzed using IDEAS software.

activity of this key C. albicans morphogentic conversion intimately linked to virulence. Although these results do not point to an exact mechanism of action of the lead compound, they are relevant to the challenging environment encountered by $C$. albicans inside the human host, which can cause stress and damage to the fungus possibly leading to filamentation as a response (Kadosh and Lopez-Ribot, 2013).

\section{In Vitro Pharmacological Profiling for the Detection of Potential Off-Target Effects of the Leading Candidate Compound}

Previously, we performed standard cytotoxicity studies using HepG2 cell lines (Romo et al., 2017) that pointed to the fact that the lead compound displays a relatively safe profile. In order to expand on potential safety liabilities and identify offtarget effects early in the process that could lead to potential undesirable effects and future safety liabilities in the clinic, and to provide additional reassurance for the potential for drug development, as well as guidance for follow-up strategies, we performed an in vitro pharmacological profiling of the of the leading 9029936 compound against 44 different targets (mostly human, including G- protein-coupled receptors, ion channels, enzymes and neurotransmitter transporters) (Whitebread et al., 2005; Hamon et al., 2009; Bowes et al., 2012). Results indicated that compound 9029936, when tested at $10 \mu \mathrm{M}$ concentration (higher than the concentrations needed to inhibit filamentation and biofilm formation) had a relatively clean profile and minimal off-target activities, leading to $50 \%$ inhibition or higher in only 2 of the total 44 assays (Figure 8). This results in a promiscuity index (the target hit rate, defined as the percentage of targets giving $>50 \%$ inhibition at $10 \mu \mathrm{M}$ ) of $<5 \%$, which would categorize this compound as "selective" (Whitebread et al., 2005; Hamon et al., 2009). We note that one of the hits is on the 5-hydroxytryptamine (serotonin) receptor 2B (5- $\left.\mathrm{HT}_{2 \mathrm{~B}}\right)$, which is linked to cardiac effects, particularly during embryonic development; whereas the other hit is on the norepinephrine transporter, linked to increased heart rate 


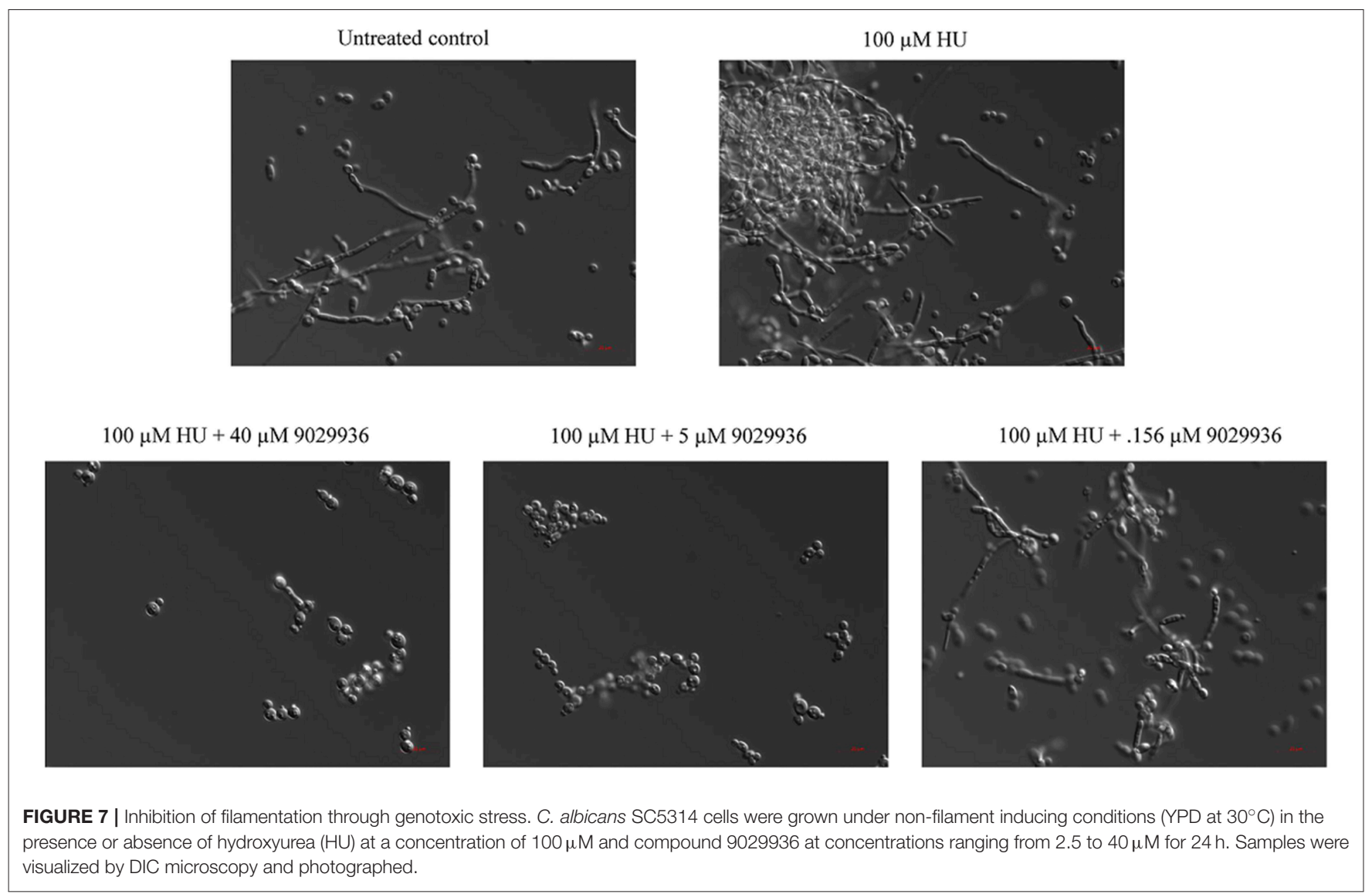

and blood pressure, as well as constipation (Whitebread et al., 2005).

\section{DISCUSSION}

The opportunistic pathogenic fungus C. albicans is capable of causing a variety of infections ranging from mucosal to lifethreatening systemic candidiasis (Fidel, 1998; Wilson et al., 2002; Hajjeh et al., 2004; Kojic and Darouiche, 2004; Thompson et al., 2010; Kim and Sudbery, 2011; Kullberg and Arendrup, 2015; Allison et al., 2016; McCarty and Pappas, 2016). These infections represent an increasing threat to an ever expanding population of immune- and medically compromised individuals and candidiasis is now the third-to-fourth most frequent nosocomial infection in US hospitals (Wright and Wenzel, 1997; Ramage et al., 2005; Schmiedel and Zimmerli, 2016). Fungal and animal cells are very similar, making antifungal discovery efforts much more arduous than those for antibacterial antibiotics. Unfortunately there is a paucity of antifungal drugs and their efficacy is limited, and as a result clinical outcomes of candidiasis remain far from ideal (Ostrosky-Zeichner et al., 2010; Perfect, 2017). Targeting pathogenetic mechanisms can expand the number of potential targets that can be exploited for antifungal drug discovery, leading to the development of novel anti-virulence approaches to antifungal therapy (Pierce et al., 2015a; Romo et al., 2017; Vila et al., 2017). Filamentation and biofilm formation constitute two of the main virulence factors associated with the ability of $C$. albicans to cause active infection (Mayer et al., 2013). Most recently our group has described a novel series of small molecule compounds with a common biaryl amide core structure that display potent inhibitory activity against C. albicans filamentation and biofilm formation (Romo et al., 2017). The leading compound in this series, compound 9029936, represents a candidate for the development of novel anti-virulence therapies against $C$. albicans infections.

In a first series of experiments we demonstrated that besides its activity against the C. albicans SC5314 laboratory strain (as expected because of its anti-virulence mode of action), the lead compound proved to be effective against a panel of $C$. albicans clinical isolates, regardless of their underlying molecular mechanism of antifungal drug resistance (i.e., modification in the target enzyme and/or overexpression of efflux pumps) (White, 1997a,b). Likewise, compound 9029936 was also active against C. albicans gain of function strains in key transcriptional activators of ergosterol biosynthesis and efflux pumps, all of which are resistant to azole antifungals (Schubert et al., 2008; Flowers et al., 2012). These results underscore the potential of the lead compound as an effective therapeutic against C. albicans infections, including those recalcitrant to therapy with current conventional antifungal drugs.

Although C. albicans remains the main etiological agent of candidiasis and is responsible for up to $70 \%$ of fungal infections, 


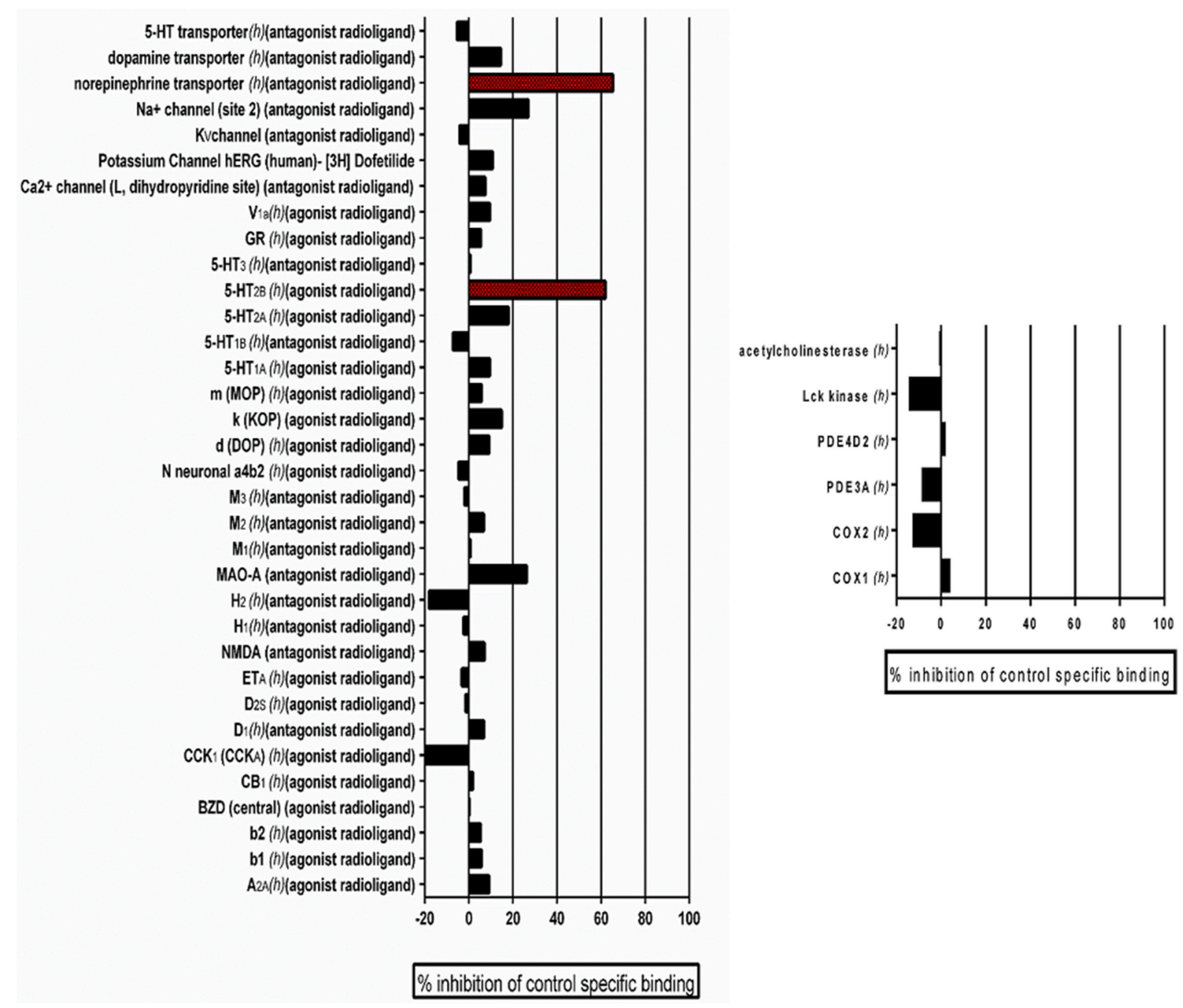

FIGURE 8 | Results of Eurofin Cerep Safety-Screen 44 Panel. In vitro pharmacological profiling and assessment of the potential for off-target interactions of the 9029936 leading compound in binding screens (Eurofins Cerep-Panlabs SafetyScreen 44). The compound was screened at a $10 \mu \mathrm{M}$ concentration in duplicate for its potential to interfere with the binding of native ligands of 44 different receptors, ion channels and enzymes. For receptor assays, compound binding was calculated as percent inhibition of the binding of a radioactively labeled ligand specific for each target. For enzyme assays, the inhibition effect was calculated as percent inhibition of control enzyme activity. Tests were performed in duplicate and results are averages of those two tests.

in the last two decades the importance of non-albicans Candida species as opportunistic pathogens has emerged (Sullivan et al., 2004, 2005; Silva et al., 2012; Priest and Lorenz, 2015). The high prevalence of non-albicans Candida species in disease could also be a reflection of their inherently higher level of resistance to certain antifungal drugs, and/or their increased propensity to develop resistance than C. albicans (Silva et al., 2012). In fact, it has been demonstrated that the selective pressure imposed by antifungal treatment can lead to the replacement of C. albicans by one of the less common species (Martinez et al., 2002). Overall, infections caused by these non-albicans Candida species are often more challenging to detect, diagnose, and treat, and often leads to high morbidity and mortality rates (Criseo et al., 2015). By definition high specificity for the target microorganism is another expected characteristic of an anti-virulence compound, due to virulence factors often being specific to a single microorganism or group of microorganisms (Rasko and Sperandio, 2010). As a result, anti-virulence approaches generally exhibit a narrower window of activity and spectrum of action, as they are only effective against the species displaying the specific virulence factor. For example, our leading compounds exert their activity by inhibiting the morphological transition from yeast to hypha, as well as filamentation-associated biofilm formation. Although these represent the two major pathogenetic mechanisms of C. albicans, other Candida species display varying degrees in their abilities to filament and form biofilms (Gilfillan et al., 1998; Ramage et al., 2001a; Jabra-Rizk et al., 2004; Brunke and Hube, 2013). As a consequence, we would expect the activity of our leading anti-virulence compound against other nonalbicans Candida species to differ widely depending on their intrinsic ability to undergo these morphogenetic transitions. Here we expanded our investigations to examine the in vitro activity of our leading compounds against different non-albicans Candida species including C. glabrata (unable to filament), C. 
tropicalis (with limited ability to filament), and C. dubliniensis (high filamentation ability, but generally lower than that of C. albicans Thompson et al., 2011). Not surprisingly, we observed the highest levels of activity only against $C$. dubliniensis, which is closely related to $C$. albicans with whom it shares a number of phenotypic characteristics, including the ability to filament and form biofilms (Gilfillan et al., 1998; Sullivan and Coleman, 1998; Ramage et al., 2001a). Although the filamentation machinery in C. dubliniensis appears to be similar to that of C. albicans, but has not been fully characterized (Gilfillan et al., 1998; Martins et al., 2007; Moran et al., 2007; Sullivan and Moran, 2011), the fact that compound 9029936 was able to inhibit C. dubliniensis filamentation under all conditions tested reinforces our previous results with $C$. albicans (Romo et al., 2017). Thus, since each medium condition stimulates a specific filamentation pathway, it is likely that the compound does not target any single signaling pathway, but rather interacts with a common component of the filamentation machinery required for filamentation under all conditions, in both C. albicans and C. dubliniensis. As described above, compound 9029936 exhibits a spectrum of action specific against C. albicans and C. dubliniensis, but not against C. glabrata or C. tropicalis, most likely related to the different filamentation capabilities exhibited by the different species. Although this could be perceived as a limitation, it would be expected that this specific activity would exert less stress on the target organism and the host microbiome. Additionally, this narrow activity further validates the anti-virulence nature of the compound.

One distinct possibility given their mode of action, is that anti-virulence agents may be used therapeutically in combination with conventional antibiotics. As described above, combinatorial therapy is widely used for viral and bacterial infections, but it is relatively uncommon in the case of fungal infections (Baddley and Pappas, 2005; Spitzer et al., 2017). Thus, we were interested in testing the activity of our compound together with existing antifungal drugs fluconazole, amphotericin B and caspofungin. We tested the effect of these combinations under all different growth conditions: inhibition of planktonic growth, inhibition of biofilm formation and against preformed biofilms. Although synergy was not widely observed, the leading compound displayed indifference when tested in combination with clinically-used antifungals. This is in contrast to combinations between azoles and echinocandins for which antagonistic effects have previously been described (Bachmann et al., 2003). Together these observations suggest that compound 9029936 could potentially be used successfully together with these antifungals, effectively combining antivirulence and conventional approaches for the treatment of C. albicans infections. Although this compound might be better administered as a prophylactic therapy, based on the drug combination results it could also be used in combinatorial therapy, a strategy which has not been fully adopted in the clinic (Baddley and Pappas, 2005). Moreover, although we have previously demonstrated the efficacy of this compound in vivo in the murine model of oral candidiasis which uses immunocompromised mice (Romo et al., 2017), a potential limitation of this type of compounds is that their use could be limited in certain immunosuppressed patients. This is probably where its use in combination could be indicated.

Another main characteristic expected from an anti-virulence compound is an overall lack of effect on growth (Pierce et al., 2015a). Cell viability studies clearly demonstrated that concentrations as high as $40 \mu \mathrm{M}$ of the lead compound (more than 20 times higher than those required to inhibit filamentation), were unable to kill or arrest cell growth of C. albicans cells, confirming that the lead compound is not toxic to fungal cells and acts by specifically disarming the fungus of its virulence factors. Although cytological profiling showed that treatment with the compound results in changes to the cell wall and vacuolar integrity, these effects are likely secondary to the main filamentation deficiency, and do not result in overall growth defects at physiological concentrations tested $(40 \mu \mathrm{M}$ or below). Also, anti-virulence approaches should, at least in theory, prevent the development of resistance since they exert much lower levels of selective pressure as compared to conventional antibiotics, including antifungals (Clatworthy et al., 2007; Rasko and Sperandio, 2010; Ling et al., 2015). Consistent with this prediction, results from serial passage experiments demonstrated that repeated exposure against compound 9029936 did not lead to changes in C. albicans susceptibility, which underscores its low potential for fostering resistance.

Besides its inhibitory activities, we have previously reported on the favorable cytotoxicity properties displayed by compound 9029936, underscoring its safety and potential for further development (Romo et al., 2017). In vitro pharmacological profiling is increasingly being used earlier in the drug development process to identify potentially undesirable off-target activities and predict clinical adverse events that could jeopardize the development of lead compounds as drug candidates (Bowes et al., 2012). The Eurofins CEREP SafetyScreen 44 panel is recommended by a number of pharmaceutical companies to identify potential pharmacological safety liabilities (Whitebread et al., 2005; Hamon et al., 2009; Bowes et al., 2012). The relatively clean profile and low promiscuity index displayed by compound 9029936 in these tests seems to confirm its potential for further development.

The use of anti-virulence molecules such as 9029936 would expand the alarmingly limited antifungal arsenal. Moreover, targeting pathogenic processes not required for cell survival should also minimize the environmental pressure on the target microorganism, which is the main reason leading to the development of resistance to antifungal agents. Additionally, due to the high specificity of this compound toward C. albicans and C. dubliniensis filamentation, it would presumably not have negative effects on the host microbiota such as those seen with other broad spectrum antimicrobials.

Altogether, our results confirm that our leading compound acts as a true anti-virulence agent, and confirm that compounds within this series hold potential for the development of novel anti-virulence strategies against candidiasis, including for infections refractory to treatment with conventional antimycotics. These novel approaches are much needed to both enhance and add diversity to the exceedingly limited antifungal 
armory currently available for the therapy of these devastating infections.

\section{AUTHOR CONTRIBUTIONS}

JR performed most in vitro experiments, CP performed initial characterization. $\mathrm{ME}$ and $\mathrm{C}-\mathrm{YH}$ helped with the imaging flow cytometry and conducted the analysis. JR, SS, and JL-R designed follow-up studies. JR, SS, and JL-R wrote and edited the manuscript.

\section{FUNDING}

This work was supported by grants numbered R01AI119554 (to JL-R) and R01AI063256 (to SS) from the National Institute of
Allergy and Infectious Diseases. Additional support was provided by the Margaret Batts Tobin Foundation, San Antonio, TX. JR is supported by the UTSA RISE-Ph.D. Trainee Program (NIH/NIGMS RISE GM60655). The funders had no role in study design, data collection and analysis, decision to publish, or preparation of the manuscript, and the content is solely the responsibility of the authors.

\section{ACKNOWLEDGMENTS}

The authors would like to thank Dr. David Rogers from the University of Tennessee Health Science Center for the gain-offunction strains and Dr. Nathan Wiederhold from the University of Texas Health Science Center San Antonio Fungal Testing Lab for the non-albicans Candida clinical isolates.

\section{REFERENCES}

Allison, D. L., Willems, H. M., Jayatilake, J. A., Bruno, V. M., Peters, B. M., and Shirtliff, M. E. (2016). Candida-bacteria interactions: their impact on human disease. Microbiol. Spectr. 4, 103-136. doi: 10.1128/microbiolspec.VMBF-0030-2016

Bachmann, S. P., Ramage, G., Vandewalle, K., Patterson, T. F., Wickes, B. L., and López-Ribot, J. L. (2003). Antifungal combinations against Candida albicans biofilms in vitro. Antimicrob. Agents Chemother. 47, 3657-3659. doi: 10.1128/AAC.47.11.3657-3659.2003

Baddley, J. W., and Pappas, P. G. (2005). Antifungal combination therapy: clinical potential. Drugs 65, 1461-1480. doi: 10.2165/00003495-200565110-00002

Blair, J. M., Webber, M. A., Baylay, A. J., Ogbolu, D. O., and Piddock, L. J. (2015). Molecular mechanisms of antibiotic resistance. Nat. Rev. Microbiol. 13, 42-51. doi: $10.1038 /$ nrmicro3380

Bowes, J., Brown, A. J., Hamon, J., Jarolimek, W., Sridhar, A., Waldron, G., et al. (2012). Reducing safety-related drug attrition: the use of in vitro pharmacological profiling. Nat. Rev. Drug Discov. 11, 909-922. doi: $10.1038 / \mathrm{nrd} 3845$

Brown, G. D., Denning, D. W., Gow, N. A., Levitz, S. M., Netea, M. G., and White, T. C. (2012). Hidden killers: human fungal infections. Sci. Transl. Med. 4:165rv113. doi: 10.1126/scitranslmed.3004404

Brunke, S., and Hube, B. (2013). Two unlike cousins: Candida albicans and C. glabrata infection strategies. Cell Microbiol. 15, 701-708. doi: $10.1111 / \mathrm{cmi} .12091$

Citiulo, F., Moran, G. P., Coleman, D. C., and Sullivan, D. J. (2009). Purification and germination of Candida albicans and Candida dubliniensis chlamydospores cultured in liquid media. FEMS Yeast Res. 9, 1051-1060. doi: 10.1111/j.1567-1364.2009.00533.x

Clatworthy, A. E., Pierson, E., and Hung, D. T. (2007). Targeting virulence: a new paradigm for antimicrobial therapy. Nat. Chem. Biol. 3, 541-548. doi: $10.1038 /$ nchembio.2007.24

Criseo, G., Scordino, F., and Romeo, O. (2015). Current methods for identifying clinically important cryptic Candida species. J. Microbiol. Methods 111, 50-56. doi: 10.1016/j.mimet.2015.02.004

d'enfert, C., and Janbon, G. (2016). Biofilm formation in Candida glabrata: What have we learnt from functional genomics approaches? FEMS Yeast Res 16, fov111. doi: 10.1093/femsyr/fov111

Fairlamb, A. H., Gow, N. A., Matthews, K. R., and Waters, A. P. (2016). Drug resistance in eukaryotic microorganisms. Nat. Microbiol. 1:16092. doi: 10.1038/nmicrobiol.2016.92

Fazly, A., Jain, C., Dehner, A. C., Issi, L., Lilly, E. A., Ali, A., et al. (2013). Chemical screening identifies filastatin, a small molecule inhibitor of Candida albicans adhesion, morphogenesis, and pathogenesis. Proc. Natl. Acad. Sci. U.S.A. 110, 13594-13599. doi: 10.1073/pnas.1305982110

Fidel, P. L. Jr. (1998). Vaginal candidiasis: review and role of local mucosal immunity. AIDS Patient Care STDS 12, 359-366. doi: 10.1089/apc.1998.12.359

Flowers, S. A., Barker, K. S., Berkow, E. L., Toner, G., Chadwick, S. G., Gygax, S. E., et al. (2012). Gain-of-function mutations in UPC2 are a frequent cause of ERG11 upregulation in azole-resistant clinical isolates of Candida albicans. Eukaryotic Cell 11, 1289-1299. doi: 10.1128/EC.00215-12

Gauwerky, K., Borelli, C., and Korting, H. C. (2009). Targeting virulence: a new paradigm for antifungals. Drug Discov. Today 14, 214-222. doi: 10.1016/j.drudis.2008.11.013

Gilfillan, G. D., Sullivan, D. J., Haynes, K., Parkinson, T., Coleman, D. C., and Gow, N. A. (1998). Candida dubliniensis: phylogeny and putative virulence factors. Microbiology 144(Pt 4), 829-838. doi: 10.1099/00221287-144-4-829

Hajjeh, R. A., Sofair, A. N., Harrison, L. H., Lyon, G. M., Arthington-Skaggs, B. A., Mirza, S. A., et al. (2004). Incidence of bloodstream infections due to Candida species and in vitro susceptibilities of isolates collected from 1998 to 2000 in a population-based active surveillance program. J. Clin. Microbiol. 42, 1519-1527. doi: 10.1128/JCM.42.4.1519-1527.2004

Hall, M. J., Middleton, R. F., and Westmacott, D. (1983). The fractional inhibitory concentration (FIC) index as a measure of synergy. J. Antimicrob. Chemother. 11, 427-433. doi: 10.1093/jac/11.5.427

Hamon, J., Whitebread, S., Techer-Etienne, V., Le Coq, H., Azzaoui, K., and Urban, L. (2009). In vitro safety pharmacology profiling: what else beyond hERG? Future Med. Chem. 1, 645-665. doi: 10.4155/fmc.09.51

Hindler, J. (1983). Strategies for antimicrobial susceptibility testing of fastidious aerobic bacteria. Am. J. Med. Technol. 49, 761-767.

Hindler, J. (1994). Non-traditional approaches for quality control of antimicrobial susceptibility tests. Adv. Exp. Med. Biol. 349, 67-85. doi: 10.1007/978-1-4757-9206-5_7

Hindler, J. (1995). “Antimicrobial susceptibility testing," in Clinical Microbiology Procedures Handbook, ed H. D. Isenberg (Washington, DC: ASM Press), p 5.18.11-15.18.20.

Hubbard, M. J., Sullivan, P. A., and Shepherd, M. G. (1985). Morphological studies of $\mathrm{N}$-acetylglucosamine induced germ tube formation by Candida albicans. Can. J. Microbiol. 31, 696-701. doi: 10.1139/m85-132

Hughes, D., and Andersson, D. I. (2015). Evolutionary consequences of drug resistance: shared principles across diverse targets and organisms. Nat. Rev. Genet. 16, 459-471. doi: 10.1038/nrg3922

Jabra-Rizk, M. A., Falkler, W. A., and Meiller, T. F. (2004). Fungal biofilms and drug resistance. Emerging Infect. Dis. 10, 14-19. doi: 10.3201/eid1001.030119

Jorgensen, J. H., Swenson, J. M., Tenover, F. C., Ferraro, M. J., Hindler, J. A., and Murray, P. R. (1994). Development of interpretive criteria and quality control limits for broth microdilution and disk diffusion antimicrobial susceptibility testing of Streptococcus pneumoniae. J. Clin. Microbiol. 32, 2448-2459.

Kadosh, D., and Lopez-Ribot, J. L. (2013). Candida albicans: adapting to succeed. Cell Host Microbe 14, 483-485. doi: 10.1016/j.chom.2013.10.016

Kim, J., and Sudbery, P. (2011). Candida albicans, a major human fungal pathogen. J. Microbiol. 49, 171-177. doi: 10.1007/s12275-011-1064-7

Kojic, E. M., and Darouiche, R. O. (2004). Candida infections of medical devices. Clin. Microbiol. Rev. 17, 255-267. doi: 10.1128/CMR.17.2.255-267.2004 
Kullberg, B. J., and Arendrup, M. C. (2015). Invasive candidiasis. N. Engl. J. Med. 373, 1445-1456. doi: 10.1056/NEJMra1315399

Lackey, E., Vipulanandan, G., Childers, D. S., and Kadosh, D. (2013). Comparative evolution of morphological regulatory functions in Candida species. Eukaryotic Cell 12, 1356-1368. doi: 10.1128/EC.00164-13

Lee, K. L., Buckley, H. R., and Campbell, C. C. (1975). An amino acid liquid synthetic medium for the development of mycellal and yeast forms of Candida albicans. Med. Mycol. 13, 148-153. doi: 10.1080/00362177585190271

Ling, L. L., Schneider, T., Peoples, A. J., Spoering, A. L., Engels, I., Conlon, B. P., et al. (2015). A new antibiotic kills pathogens without detectable resistance. Nature 517, 455-459. doi: 10.1038/nature14098

Liu, H., Köhler, J., and Fink, G. R. (1994). Suppression of hyphal formation in Candida albicans by mutation of a STE12 homolog. Science 266, 1723-1726. doi: $10.1126 /$ science.7992058

Lopez-Ribot, J. L. (2005). Candida albicans biofilms: more than filamentation. Curr. Biol. 15, R453-R455. doi: 10.1016/j.cub.2005.06.020

Martinez, M., López-Ribot, J. L., Kirkpatrick, W. R., Coco, B. J., Bachmann, S. P., and Patterson, T. F. (2002). Replacement of Candida albicans with C. dubliniensis in human immunodeficiency virus-infected patients with oropharyngeal candidiasis treated with fluconazole. J. Clin. Microbiol. 40, 3135-3139. doi: 10.1128/JCM.40.9.3135-3139.2002

Martins, M., Henriques, M., Azeredo, J., Rocha, S. M., Coimbra, M. A., and Oliveira, R. (2007). Morphogenesis control in Candida albicans and Candida dubliniensis through signaling molecules produced by planktonic and biofilm cells. Eukaryotic Cell 6, 2429-2436. doi: 10.1128/EC.00252-07

Mayer, F. L., Wilson, D., and Hube, B. (2013). Candida albicans pathogenicity mechanisms. Virulence 4, 119-128. doi: 10.4161/viru.22913

McCarty, T. P., and Pappas, P. G. (2016). Invasive candidiasis. Infect. Dis. Clin. North Am. 30, 103-124. doi: 10.1016/j.idc.2015.10.013

McManus, B. A., Coleman, D. C., Moran, G., Pinjon, E., Diogo, D., Bougnoux, M. E., et al. (2008). Multilocus sequence typing reveals that the population structure of Candida dubliniensis is significantly less divergent than that of Candida albicans. J. Clin. Microbiol. 46, 652-664. doi: 10.1128/JCM.01574-07

Moran, G. P., Maccallum, D. M., Spiering, M. J., Coleman, D. C., and Sullivan, D. J. (2007). Differential regulation of the transcriptional repressor NRG1 accounts for altered host-cell interactions in Candida albicans and Candida dubliniensis. Mol. Microbiol. 66, 915-929. doi: 10.1111/j.1365-2958.2007.05965.x

Odds, F. C., Brown, A. J. P., and Gow, N. A. R. (2003). Antifungal agents: mechanisms of action. Trends Microbiol. 11, 272-279. doi: 10.1016/S0966-842X(03)00117-3

Ostrosky-Zeichner, L., Casadevall, A., Galgiani, J. N., Odds, F. C., and Rex, J. H. (2010). An insight into the antifungal pipeline: selected new molecules and beyond. Nat. Rev. Drug Discov. 9, 719-727. doi: 10.1038/nrd3074

O’Toole, G. A. (2011). Microtiter dish biofilm formation assay. J. Vis. Exp. 30:2437. doi: $10.3791 / 2437$

Perea, S., Lopez-Ribot, J. L., Kirkpatrick, W. R., Mcatee, R. K., Santillan, R. A., Martinez, M., et al. (2001). Prevalence of molecular mechanisms of resistance to azole antifungal agents in Candida albicans strains displaying high-level fluconazole resistance isolated from human immunodeficiency virus-infected patients. Antimicrob. Agents Chemother. 45, 2676-2684. doi: 10.1128/AAC.45.10.2676-2684.2001

Perfect, J. R. (2017). The antifungal pipeline: a reality check. Nat. Rev. Drug Discov. 16, 603-616. doi: 10.1038/nrd.2017.46

Pierce, C. G., Chaturvedi, A. K., Lazzell, A. L., Powell, A. T., Saville, S. P., Mchardy, S. F., et al. (2015a). A novel small molecule inhibitor of biofilm formation, filamentation and virulence with low potential for the development of resistance. NPJ Biofilms Microb. 1:15012. doi: 10.1038/npjbiofilms.2015.12

Pierce, C. G., and Lopez-Ribot, J. L. (2013). Candidiasis drug discovery and development: new approaches targeting virulence for discovering and identifying new drugs. Expert Opin. Drug Discov. 8, 1117-1126. doi: $10.1517 / 17460441.2013 .807245$

Pierce, C. G., Srinivasan, A., Ramasubramanian, A. K., and López-Ribot, J. L. (2015b). From biology to drug development: new approaches to combat the threat of fungal biofilms. Microbiol. Spectr. 3, 373-388. doi: 10.1128/microbiolspec.MB-0007-2014

Pierce, C. G., Srinivasan, A., Uppuluri, P., Ramasubramanian, A. K., and LopezRibot, J. L. (2013). Antifungal therapy with an emphasis on biofilms. Curr. Opin. Pharmacol. 13, 726-730. doi: 10.1016/j.coph.2013.08.008
Pierce C. G., Srinivasan A., Uppuluri P., Ramasubramanian A. K., and López-Ribot J. L. (2014). "Inhibition of fungal biofilms," in Antibiofilm Agents, Springer Series on Biofilms, Vol. 8, eds K. Rumbaugh and I. Ahmad. (Berlin; Heidelberg: Springer), 273-289.

Pierce, C. G., Uppuluri, P., Tristan, A. R., Wormley, F. L. Jr., Mowat, E., Ramage, G., et al. (2008). A simple and reproducible 96-well plate-based method for the formation of fungal biofilms and its application to antifungal susceptibility testing. Nat. Protoc. 3, 1494-1500. doi: 10.1038/nprot.2008.141

Pierce, C. G., Uppuluri, P., Tummala, S., and Lopez-Ribot, J. L. (2010). A 96 well microtiter plate-based method for monitoring formation and antifungal susceptibility testing of Candida albicans biofilms. J. Vis. Exp. 21:2287. doi: $10.3791 / 2287$

Priest, S. J., and Lorenz, M. C. (2015). Characterization of virulence-related phenotypes in Candida species of the CUG clade. Eukaryotic Cell 14, 931-940. doi: 10.1128/EC.00062-15

Ramage, G., Saville, S. P., Thomas, D. P., and López-Ribot, J. L. (2005). Candida biofilms: an update. Eukaryotic Cell 4, 633-638. doi: 10.1128/EC.4.4.633-638.2005

Ramage, G., Vande Walle, K., Wickes, B. L., and Lopez-Ribot, J. L. (2001a). Biofilm formation by Candida dubliniensis. J. Clin. Microbiol. 39, 3234-3240. doi: 10.1128/JCM.39.9.3234-3240.2001

Ramage, G., Vande Walle, K., Wickes, B. L., and López-Ribot, J. L. (2001b). Standardized method for in vitro antifungal susceptibility testing of Candida albicans biofilms. Antimicrob. Agents Chemother. 45, 2475-2479. doi: 10.1128/AAC.45.9.2475-2479

Ramage, G., Vandewalle, K., Wickes, B. L., and López-Ribot, J. L. (2001c). Characteristics of biofilm formation by Candida albicans. Rev. Iberoam. Micol. 18, 163-170. Available online at: https://4fnfl92psu9e3d280z3z4m8qwpengine.netdna-ssl.com/wp-content/uploads/research/biofilm-formation. pdf

Rasko, D. A., and Sperandio, V. (2010). Anti-virulence strategies to combat bacteria-mediated disease. Nat. Rev. Drug Discov. 9, 117-128. doi: $10.1038 / \mathrm{nrd} 3013$

Romani, L., Bistoni, F., and Puccetti, P. (2003). Adaptation of Candida albicans to the host environment: the role of morphogenesis in virulence and survival in mammalian hosts. Curr. Opin. Microbiol. 6, 338-343. doi: 10.1016/S1369-5274(03)00081-X

Romani, L., Zelante, T., Palmieri, M., Napolioni, V., Picciolini, M., Velardi, A., et al. (2015). The cross-talk between opportunistic fungi and the mammalian host via microbiota's metabolism. Semin. Immunopathol. 37, 163-171. doi: 10.1007/s00281-014-0464-2

Romo, J. A., Pierce, C. G., Chaturvedi, A. K., Lazzell, A. L., Mchardy, S. F., Saville, S. P., et al. (2017). Development of anti-virulence approaches for candidiasis via a novel series of small-molecule inhibitors of Candida albicans filamentation. MBio 8:e01991-17. doi: 10.1128/mBio.01991-17

Salvatori, O., Puri, S., Tati, S., and Edgerton, M. (2016). Innate immunity and saliva in Candida albicans-mediated oral diseases. J. Dent. Res. 95, 365-371. doi: $10.1177 / 0022034515625222$

Sardi, J. C., Scorzoni, L., Bernardi, T., Fusco-Almeida, A. M., and Mendes Giannini, M. J. (2013). Candida species: current epidemiology, pathogenicity, biofilm formation, natural antifungal products and new therapeutic options. J. Med. Microbiol. 62, 10-24. doi: 10.1099/jmm.0.045054-0

Schmiedel, Y., and Zimmerli, S. (2016). Common invasive fungal diseases: an overview of invasive candidiasis, aspergillosis, cryptococcosis, and Pneumocystis pneumonia. Swiss Med. Wkly. 146:w14281. doi: $10.4414 / \mathrm{smw} .2016 .14281$

Schubert, S., Rogers, P. D., and Morschhauser, J. (2008). Gain-of-function mutations in the transcription factor $M R R 1$ are responsible for overexpression of the MDR1 efflux pump in fluconazole-resistant Candida dubliniensis strains. Antimicrob. Agents Chemother. 52, 4274-4280. doi: 10.1128/AAC.00740-08

Shareck, J., and Belhumeur, P. (2011). Modulation of morphogenesis in Candida albicans by various small molecules. Eukaryotic Cell 10, 1004-1012. doi: 10.1128/EC.05030-11

Shepherd, M. G., Yin, C. Y., Ram, S. P., and Sullivan, P. A. (1980). Germ tube induction in Candida albicans. Can. J. Microbiol. 26, 21-26. doi: $10.1139 / \mathrm{m} 80-004$

Silva, S., Negri, M., Henriques, M., Oliveira, R., Williams, D. W., and Azeredo, J. (2012). Candida glabrata, Candida parapsilosis and Candida tropicalis: biology, 
epidemiology, pathogenicity and antifungal resistance. FEMS Microbiol. Rev. 36, 288-305. doi: 10.1111/j.1574-6976.2011.00278.x

Spiering, M. J., Moran, G. P., Chauvel, M., Maccallum, D. M., Higgins, J., Hokamp, K., et al. (2010). Comparative transcript profiling of Candida albicans and Candida dubliniensis identifies $S F L 2$, a C. albicans gene required for virulence in a reconstituted epithelial infection model. Eukaryot Cell 9, 251-265. doi: 10.1128/EC.00291-09

Spitzer, M., Robbins, N., and Wright, G. D. (2017). Combinatorial strategies for combating invasive fungal infections. Virulence 8, 169-185. doi: $10.1080 / 21505594.2016 .1196300$

Stokes, C., Moran, G. P., Spiering, M. J., Cole, G. T., Coleman, D. C., and Sullivan, D. J. (2007). Lower filamentation rates of Candida dubliniensis contribute to its lower virulence in comparison with Candida albicans. Fungal Genet. Biol. 44, 920-931. doi: 10.1016/j.fgb.2006. 11.014

Sullivan, D., and Coleman, D. (1998). Candida dubliniensis: characteristics and identification. J. Clin. Microbiol. 36, 329-334.

Sullivan, D. J., and Moran, G. P. (2011). Differential virulence of Candida albicans and C. dubliniensis: a role for Tor1 kinase? Virulence 2, 77-81. doi: $10.4161 /$ viru.2.1.15002

Sullivan, D. J., Moran, G. P., and Coleman, D. C. (2005). Candida dubliniensis: ten years on. FEMS Microbiol. Lett. 253, 9-17. doi: 10.1016/j.femsle.2005. 09.015

Sullivan, D. J., Moran, G. P., Pinjon, E., Al-Mosaid, A., Stokes, C., Vaughan, C., et al. (2004). Comparison of the epidemiology, drug resistance mechanisms, and virulence of Candida dubliniensis and Candida albicans. FEMS Yeast Res. 4, 369-376. doi: 10.1016/S1567-1356(03) 00240-X

Thompson, D. S., Carlisle, P. L., and Kadosh, D. (2011). Coevolution of morphology and virulence in Candida species. Eukaryotic Cell 10, 1173-1182. doi: 10.1128/EC.05085-11

Thompson, G. R. III., Patel, P. K., Kirkpatrick, W. R., Westbrook, S. D., Berg, D., Erlandsen, J., et al. (2010). Oropharyngeal candidiasis in the era of antiretroviral therapy. Oral Surg. Oral Med. Oral Pathol. Oral Radiol. Endod. 109, 488-495. doi: 10.1016/j.tripleo.2009. 11.026
Vila, T., Romo, J. A., Pierce, C. G., Mchardy, S. F., Saville, S. P., and LopezRibot, J. L. (2017). Targeting Candida albicans filamentation for antifungal drug development. Virulence 8, 150-158. doi: 10.1080/21505594.2016.1197444

White, T. C. (1997a). Increased mRNA levels of ERG16, CDR, and MDR1 correlate with increases in azole resistance in Candida albicans isolates from a patient infected with human immunodeficiency virus. Antimicrob. Agents Chemother. $41,1482-1487$.

White, T. C. (1997b). The presence of an R467K amino acid substitution and loss of allelic variation correlate with an azole-resistant lanosterol 14alpha demethylase in Candida albicans. Antimicrob. Agents Chemother. 41, $1488-1494$.

Whitebread, S., Hamon, J., Bojanic, D., and Urban, L. (2005). Keynote review: in vitro safety pharmacology profiling: an essential tool for successful drug development. Drug Discov. Today 10, 1421-1433. doi: 10.1016/S1359-6446(05)03632-9

Wilson, L. S., Reyes, C. M., Stolpman, M., Speckman, J., Allen, K., and Beney, J. (2002). The direct cost and incidence of systemic fungal infections. Value Health 5, 26-34. doi: 10.1046/j.1524-4733.2002.51108.x

Wright, W. L., and Wenzel, R. P. (1997). Nosocomial Candida. Epidemiology, transmission, and prevention. Infect Dis Clin North Am 11, 411-425. doi: 10.1016/S0891-5520(05)70363-9

Zhang, Q., Tao, L., Guan, G., Yue, H., Liang, W., Cao, C., et al. (2016). Regulation of filamentation in the human fungal pathogen Candida tropicalis. Mol. Microbiol. 99, 528-545. doi: $10.1111 / \mathrm{mmi} .13247$

Conflict of Interest Statement: The authors declare that the research was conducted in the absence of any commercial or financial relationships that could be construed as a potential conflict of interest.

Copyright $\odot 2018$ Romo, Pierce, Esqueda, Hung, Saville and Lopez-Ribot. This is an open-access article distributed under the terms of the Creative Commons Attribution License (CC BY). The use, distribution or reproduction in other forums is permitted, provided the original author(s) and the copyright owner(s) are credited and that the original publication in this journal is cited, in accordance with accepted academic practice. No use, distribution or reproduction is permitted which does not comply with these terms. 